\title{
Desmoplastic Crosstalk in Pancreatic Ductal Adenocarcinoma Is Reflected by Different Responses of Panc-1, MIAPaCa-2, PaTu-8902, and CAPAN-2 Cell Lines to Cancer-associated/Normal Fibroblasts
}

\author{
ŠTEPÁN NOVÁK ${ }^{1,2}$, MICHAL KOLÁŘ ${ }^{3}$, ARPÁD SZABÓ ${ }^{4}$, ZDENA VERNEROVÁ ${ }^{4}$, LUKÁŠ LACINA ${ }^{1,5,6}$, \\ HYNEK STRNAD $^{3}$, JANA ŠÁCHOVÁ ${ }^{3}$, MILUŠE HRADILOVÁ ${ }^{3}$, JAN HAVRÁNEK ${ }^{3,7}$, MICHAL ŠPANKO ${ }^{1,8}$, \\ MATÚŠ ČOMA ${ }^{9,10}$, LUKÁŠ URBAN ${ }^{10,11}$, MIRIAM KAŇUCHOVÁ ${ }^{11}$, NIKOLA MELEGOVÁ ${ }^{11}$, \\ ROBERT GÜRLICH ${ }^{12}$, JOSEF DVOŘÁK ${ }^{13}$, KAREL SMETANA JR. ${ }^{1,5}$, PETER GÁL ${ }^{10,11,14}$ and PAVOL SZABO ${ }^{1,5,10}$ \\ ${ }^{1}$ Institute of Anatomy, First Faculty of Medicine, Charles University, Prague, Czech Republic; \\ ${ }^{2}$ Department of Otorhinolaryngology, Head and Neck Surgery, First Faculty of Medicine, \\ Charles University and University Hospital Motol, Prague, Czech Republic; \\ ${ }^{3}$ Laboratory of Genomics and Bioinformatics, \\ Institute of Molecular Genetics of the Czech Academy of Sciences, Prague, Czech Republic; \\ ${ }^{4}$ Department of Pathology, Third Faculty of Medicine, \\ Charles University and University Hospital Královske Vinohrady, Prague, Czech Republic; \\ ${ }^{5}$ BIOCEV, First Faculty of Medicine, Charles University, Vestec, Czech Republic; \\ ${ }^{6}$ Department of Dermatology and Venereology, First Faculty of Medicine, \\ Charles University and General University Hospital in Prague, Prague, Czech Republic; \\ ${ }^{7}$ Department of Informatics and Chemistry, Faculty of Chemical Technology, \\ University of Chemistry and Technology, Prague, Czech Republic; \\ ${ }^{8}$ Department of Stomatology, First Faculty of Medicine, \\ Charles University and General University Hospital in Prague, Prague, Czech Republic; \\ ${ }^{9}$ Department of Pharmacology, Pavol Jozef Šafárik University, Košice, Slovak Republic; \\ ${ }^{10}$ Department of Biomedical Research, East-Slovak Institute of Cardiovascular Diseases, Košice, Slovak Republic; \\ ${ }^{11}$ Laboratory of Cell Interactions, Center of Clinical and Preclinical Research MediPark, \\ Pavol Jozef Šafárik University, Košice, Slovak Republic; \\ ${ }^{12}$ Department of Surgery, Third Faculty of Medicine, \\ Charles University and University Hospital Královske Vinohrady, Prague, Czech Republic; \\ ${ }^{13}$ Department of Oncology, First Faculty of Medicine, \\ Charles University and Thomayer Hospital, Prague, Czech Republic; \\ ${ }^{14}$ Prague Burn Centre, Third Faculty of Medicine, \\ Charles University and University Hospital Královske Vinohrady, Prague, Czech Republic
}

This article is freely accessible online.

Correspondence to: Pavol Szabo, Institute of Anatomy, First Faculty of Medicine, Charles University, U nemocnice 3, 12800 Prague 2, Czech Republic. Tel: +420 224965872, e-mail: pavol.szabo@1f1.cuni.cz or Peter Gál, Laboratory of Cell Interactions MediPark and East-Slovak Institute of Cardiovascular Diseases, Inc., Trieda SNP 1, 04011 Košice, Slovak Republic. Tel: +421 552343533, Fax: +421 557891613, e-mail: pgal@vusch.sk, galovci@yahoo.com

Key Words: Epithelial-mesenchymal interaction, tumor microenvironment, cancer stem cell, tumor stroma, pancreas.

\begin{abstract}
Background/Aim: Pancreatic ductal adenocarcinoma (PDAC) still represents one of the most aggressive cancers. Understanding of the epithelial-mesenchymal crosstalk as a crucial part of the tumor microenvironment should pave the way for therapies to improve patient survival rates. Well-established cell lines present a useful and reproducible model to study PDAC biology. However, the tumor-stromal interactions between cancer cells and cancer-associated fibroblasts (CAFs) are still poorly understood. Materials and Methods: We studied interactions between four PDAC cell lines (Panc-1, CAPAN-2, MIAPaCa-2, and PaTu-8902) and conditioned media derived from primary cultures of normal fibroblasts/PDAC-derived
\end{abstract}


CAFs (PANFs). Results: When the tested PDAC cell lines were stimulated by PANF-derived conditioned media, the most aggressive behavior was acquired by the Panc-1 cell line (increased number and size of colonies, remaining expression of vimentin and keratin 8 as well as increase of epithelial-tomesenchymal polarization markers), whereas PaTu-8902 cells were rather inhibited. Of note, administration of the conditioned media to MIAPaCa-2 cells resulted in an inverse effect on the size and number of colonies, whereas CAPAN-2 cells were rather stimulated. To explain the heterogeneous pattern of the observed PDAC crosstalk at the in vitro level, we further compared the phenotype of primary cultures of cells derived from ascitic fluid with that of the tested PDAC cell lines, analyzed tumor samples of PDAC patients, and performed gene expression profiling of PANFs. Immuno-cyto/histo-chemical analysis found specific phenotype differences within the group of examined patients and tested PDAC cell lines, whereas the genomic approach in PANFs found the key molecules (IL6, IL8, MFGE8 and periostin) that may contribute to the cancer aggressive behavior. Conclusion: The desmoplastic patient-specific regulation of cancer cells by CAFs (also demonstrated by the heterogeneous response of PDAC cell lines to fibroblasts) precludes simple targeting and development of an effective treatment strategy and rather requires establishment of an individualized tumor-specific treatment protocol.

Pancreatic ductal adenocarcinoma (PDAC) is one of the most aggressive tumors. Despite effort in pancreatic cancer research, the mortality to incidence ratio has not experienced remarkable revision over the last few decades; thus, PDAC represents the fourth leading cause of cancer-related death $(1$, 2 ). The five-year survival rate remains around 5\% and the one-year rate achieves a non-promising level of only $20 \%$ (3). Unfortunately, the incidence is rising worldwide and an unfavorable two-fold increase may be expected by 2030 (4). The absence of efficient non-invasive screening markers [e.g. from peripheral blood (5)], late diagnosis, and high resistance of PDAC to current therapy has been associated to this poor prognosis. The only effective treatment represents surgical removal of the tumor. However, this is possible only in less than $20 \%$ of patients, since in the majority of patients cancer cells have already spread to local lymph nodes and the liver $(6,7)$. Subsequent adjuvant gemcitabine monotherapy was the only treatment option available for many years (8). More recently, it has been shown that gemcitabine in combination with FOLFIRINOX and nab-paclitaxel is more effective than the monotherapy, but only with slightly improved survival rates and at costs of higher toxicity (9).

Preclinical models, including epithelial cancer cell lines, present a useful tool to find effective strategies for early disease detection and/or treatment $(10,11)$. However, PDAC is a unique model of cancer-stroma crosstalk, as the malignant cells represent only a minority of the population (around $10 \%$ ) within the tumor, with still poorly understood interactions between cancer (epithelial) cell and cancerassociated fibroblasts (CAFs). In this line of evidence, wellestablished PDAC cell lines struggle to reproduce the interactions within the tumor microenvironment (TME), which seems to play a pivotal role in the progression of this highly immunosuppressive, hypoxic and desmoplastic cancer $(12,13)$. The dominant population of the stroma are $\alpha$ smooth muscle actin ( $\alpha$-SMA)-expressing CAFs. Most of the CAFs arise from activated pancreatic stellate cells and secrete extracellular matrix (ECM) proteins, as well as numerous factors favoring tumor growth and spreading (1418). The stroma also forms an effective physical barrier to the delivery of anti-neoplastic drugs (19). On the other hand, the highly immunosuppressive TME in PDAC is related to the presence of myeloid-derived suppressor cells, M2-type macrophages, and Foxp $3^{+}$regulatory $\mathrm{T}$ lymphocytes and the absence of effector $\mathrm{CD} 4^{+}$and $\mathrm{CD} 8^{+} \mathrm{T}$ cells (20-22).

It has been suggested that targeting the TME may be found promising in the fight against this fatal disease (23), but intensive research has not been successful to fully uncover the balance between the bad and good effects of the tumor-stroma crosstalk in PDAC (24-27). Therefore, the present study aimed to compare interactions between four PDAC cell lines (Panc-1, CAPAN-2, MIAPaCa-2 and PaTu8902) and primary cultures of PDAC-derived CAFs (PANFs)/normal fibroblasts (as a control). To explain the heterogeneous pattern of the observed PDAC crosstalk at the in vitro level, we also examined primary cultures of cells derived from ascitic fluid, analyzed tumor samples (at the histological level) of PDAC patients and performed gene expression profiling of PANFs. The obtained sets of data point to heterogeneous regulation of cancer cells by CAFs, which at the current state-of-art medicine preclude simple targeting and development of an effective treatment strategy.

\section{Materials and Methods}

Cell lines. Pancreatic cell lines CAPAN-2, MIAPaCa-2, and PaTu-8902 were obtained as a friendly gift from prof. Libor Vítek, Institute of Medical Biochemistry and Laboratory Diagnostics, Charles University, Prague. The Panc-1 cell line was purchased from ATCC (CRL-1469, Old Town Manassas, VA, USA). The CAPAN-2 cell line was cultivated in McCoy medium (BioConcept, Allschwil, Switzerland) supplemented with $10 \%$ fetal bovine serum (FBS) and ATB (penicillin/streptomycin, both from Biochrom, Berlin Germany) at $37^{\circ} \mathrm{C}$ and $5 \% \mathrm{CO}_{2}$. All other tested cell lines were cultured in Dulbecco's modified Eagle's medium (DMEM) $+10 \%$ FBS and ATB (all Biochrom) at $37^{\circ} \mathrm{C}$ and $5 \% \mathrm{CO}_{2}$. Cell lines were seeded on microscope supporting glass at a density of 7,500 cells $/ \mathrm{cm}^{2}$ and cultured for $24 \mathrm{~h}$. They were used for immunocytochemical inspection; see IHC of cultured cells and tissues.

Human keratinocyte cell line $\mathrm{HaCaT}$ (28) was used as a negative control for the western blot analysis of skin and PDAC-derived fibroblasts. PDAC cell lines were seeded at a density of 5,500 cells $/ \mathrm{cm}^{2}$ and cultivated for $120 \mathrm{~h}$. After 48 and $120 \mathrm{~h}$, respectively, 
Novák et al: Crosstalk in Pancreatic Ductal Adenocarcinoma

Table I. Characteristics of pancreatic ductal adenocarcinoma patients - donors of PDAC-derived cancer-associated fibroblasts and cells isolated from ascitic fluid.

\begin{tabular}{|c|c|c|c|c|c|}
\hline & Patient & Gender & Age (years) & Location & Classification \\
\hline \multirow[t]{10}{*}{ Donors of PANFs } & $\mathrm{P} 1$ & Female & 72 & Head & T3/N0/M0 \\
\hline & $\mathrm{P} 2$ & Female & 50 & Body & T3/N1/M1 (liver) \\
\hline & P3 & Male & 60 & Body & $\mathrm{T} 3 / \mathrm{N} 1 / \mathrm{M} 0$ \\
\hline & $\mathrm{P} 4$ & Female & 80 & Head & $\mathrm{T} 3 / \mathrm{N} 0 / \mathrm{M} 0$ \\
\hline & P5 & Male & 56 & Body & $\mathrm{T} 3 / \mathrm{N} 1 / \mathrm{M} 0$ \\
\hline & P7 & Female & 78 & Body & T3/N1/M1 (liver) \\
\hline & P8 & Male & 74 & Head & $\mathrm{T} 3 / \mathrm{N} 0 / \mathrm{M} 0$ \\
\hline & P9 & Male & 77 & Body & T3/N0/M0 \\
\hline & P10 & Female & 68 & Head & $\mathrm{T} 4 / \mathrm{N} 0 / \mathrm{M} 0$ \\
\hline & P11 & Male & 63 & Head & T3/N1/M0 \\
\hline \multirow[t]{4}{*}{ Donors of cells from ascitic fluid } & $\mathrm{A} 1$ & Female & 65 & Head & T4/N1/M1 (liver) \\
\hline & $\mathrm{A} 2$ & Female & 70 & Body & T4/N1/M1 (peritoneum) \\
\hline & $\mathrm{A} 3$ & Female & 65 & Head & $\mathrm{T} 4 / \mathrm{N} 1 / \mathrm{M} 0$ \\
\hline & A4 & Male & 60 & Head & T3/N1/M1 (liver) \\
\hline
\end{tabular}

PANF: Cancer-associated fibroblasts derived from PDAC; PDAC: pancreatic ductal adenocarcinoma; TNM: tumor, node, metastasis.

cultivation media were harvested, centrifuged at $400 \mathrm{~g}$, aliquots of supernatants stored in small tubes at $-20^{\circ} \mathrm{C}$ for further ELISA measurement.

Human primary cultures of cells and tissue sample collection. All human-derived material was obtained with informed consent of patients and with approval of the Ethical Committee of the University Hospital Královské Vinohrady in agreement with the Declaration of Helsinki (29).

Human fibroblasts (HFs) were isolated (30) from the skin of healthy donors who underwent routine aesthetic surgery at the Department of Aesthetic Surgery, Third Faculty of Medicine, Charles University (Prague, Czech Republic). HF cultures were expanded in DMEM supplemented with $10 \%$ FBS (both from Biochrom) and penicillin $(100 \mathrm{U} / \mathrm{ml}) /$ streptomycin $(100 \mu \mathrm{g} / \mathrm{ml}$; both from Biochrom) at $37^{\circ} \mathrm{C}$ with $5 \% \mathrm{CO}_{2}$ in humidified atmosphere.

Tumor samples of PDAC were obtained from the Department of Pathology, Third Faculty of Medicine, Charles University and University Hospital Kralovské Vinohrady in Prague. PANFs were isolated from 11 patients (P1-P11, Table I) based on the protocol described earlier $(30,31)$. The membership to the fibroblast family was verified by immunofluorescent analysis: vimentin ${ }^{+}$, keratins-, CD34-, CD45-, ${ }^{-}$MTFF$^{-}$, HMB45-, Melan-A ${ }^{-}$and western blot: high molecular weight cytokeratin ${ }^{-}$, vimentin $^{+}$, PDGFR- $\beta^{+}$. The remaining tissue of each tumor sample was processed for basic histology (fixation in $4 \%$ buffered formaldehyde, dehydration using a series of solutions with increasing concentration of ethanol, paraffin embedding, sectioning, and staining with hematoxylin and eosin) and immunohistochemistry (see bellow; IHC of cultured cells and tissues).

For further crosstalk experiments, fibroblasts prepared from two patients (P10 and P11) were selected. The presence of $\alpha$-SMA, Ki67 and nestin was detected in both studied primary cultures. For ethical reasons, we were not able to obtain normal fibroblasts/stellate cells from healthy pancreas, and thus PANFs were compared to HFs and MELFs (representatives of other types of CAFs). They were isolated and characterized similarly as the PDAC fibroblasts (30). All studied fibroblasts were seeded on cover slips at a density of $1,500 \mathrm{cells} / \mathrm{cm}^{2}$ and cultured for 120 hours. The slides were then washed three times with phosphate-buffered saline (PBS), dried and stored at $-20^{\circ} \mathrm{C}$. Subsequently, cells were processed for immunofluorescence and brightfield microscopy, see IF and IHC of cultured cells and tissues. In addition, secretion of IL6, IL8 and MFGE8 by fibroblasts into the culture media was measured after 48 and $120 \mathrm{~h}$ of cultivation by ELISA.

Ascitic cells. Ascites from patients with end-stage PDAC (Table I) were obtained at the Department of Oncology, Thomayer Hospital, Prague. Ascitic cell suspension was centrifuged at $400 \mathrm{~g}$ and resuspended in sterile PBS, and centrifuged again under the same conditions. The cell pellet was resuspended in fresh DMEM (Biochrom) supplemented with 10\% FBS (Biochrom) and cultured at $37^{\circ} \mathrm{C}$ and $5 \% \mathrm{CO}_{2}$ in humidified atmosphere for five days. Following trypsinization (trypsin, Sigma-Aldrich, St. Louis, MO, USA), cells were seeded on microscope coverslip slides at a density of 20,000 cells $/ \mathrm{cm}^{2}$ and cultivated in DMEM + 10\% FBS + ATB (penicillin/streptomycin, Biochrom) for $24 \mathrm{~h}$. Subsequently, cells were processed for immunocytochemistry, see IHC of cultured cells and tissues.

Conditioned media from PANFs and HFs. To evaluate the biological effect of PANFs/HFs mediated by soluble agents on the studied pancreatic cell lines, we used a model based on the application of conditioned media. CAF/HF cells were seeded at a density of 6,000 cells $/ \mathrm{cm}^{2}$. After reaching $80 \%$ confluence, the medium was changed to fresh DMEM or McCoy medium that was conditioned for the next $24 \mathrm{~h}$. Finally, the enriched media were centrifuged at $400 \mathrm{~g}$, the supernatants were collected in new flasks, stored at $+4^{\circ} \mathrm{C}$ for no longer than $24 \mathrm{~h}$, and used for PDAC cell conditioning.

PANC-1, MIAPaCa-2 and PaTu-8902 cell lines were seeded on cover slips at a density of 5,000 cells $/ \mathrm{cm}^{2}$ in DMEM CAF- or HFderived conditioned media for $120 \mathrm{~h}$, whereas the CAPAN-2 cell line was seeded at $10,000 / \mathrm{cm}^{2}$ and cultured in McCoy CAF- or HF-derived conditioned media. After 48 and $120 \mathrm{~h}$ we collected samples of the culture medium that were processed for ELISA examination. Finally, the cover slips were washed three times with PBS dried, and stored at $-20^{\circ} \mathrm{C}$, and subsequently processed for immunofluorescence, see IF of cultured cells. 
Table II. List of antibodies used for western blot.

\begin{tabular}{|c|c|c|c|c|}
\hline Primary antibody & Host & Isotype & Clonality & Produced by \\
\hline E-cadherin & Rat & $\operatorname{IgG}$ & Monoclonal & eBioscience, San Diego, CA, USA \\
\hline $\mathrm{N}$-cadherin & Rabbit & $\operatorname{IgG}$ & Polyclonal & Invitrogen, Carslbad, CA, USA \\
\hline Keratin 8 & Mouse & $\operatorname{IgG}$ & Monoclonal & Invitrogen, Carslbad, CA, USA \\
\hline Keratin 14 & Rabbit & $\mathrm{IgG}$ & Polyclonal & Invitrogen, Carslbad, CA, USA \\
\hline Keratin 19 & Mouse & $\mathrm{IgG}$ & Monoclonal & Invitrogen, Carslbad, CA, USA \\
\hline PDGFR- $\beta$ & Rabbit & $\operatorname{IgG}$ & Monoclonal & CST, Danvers, MA, USA \\
\hline Slug & Rabbit & $\mathrm{IgG}$ & Polyclonal & Invitrogen, Carslbad, CA, USA \\
\hline Snail & Mouse & $\operatorname{IgG}$ & Monoclonal & eBioscience, San Diego, CA, USA \\
\hline Vimentin & Rabbit & $\mathrm{IgG}$ & Monoclonal & CST, Danvers, MA, USA \\
\hline WSC & Rabbit & $\operatorname{IgG}$ & Polyclonal & Abcam, Cambridge, UK \\
\hline$\beta$-actin & Rabbit & $\operatorname{IgG}$ & Monoclonal & CST, Danvers, MA, USA \\
\hline Secondary antibody & Host & Isotype & & Produced by \\
\hline Anti-rabbit, HRP-linked & Goat & $\operatorname{IgG}$ & & CST, Danvers, MA, USA \\
\hline Anti-rat, HRP-linked & Goat & IgG & & CST, Danvers, MA, USA \\
\hline Anti-mouse, HRP-linked & Horse & $\operatorname{IgG}$ & & CST, Danvers, MA, USA \\
\hline
\end{tabular}

WSC: Wide-spectrum cytokeratin, PDGFR- $\beta$ : platelet-derived growth factor receptor beta; HRP: horseradish peroxidase; IgG: immunoglobulin G.

For western blot analysis, cells were seeded at a density of $5,000 / \mathrm{cm}^{2}$ (MIAPaCa-2, PaTu-8902 and Panc-1) or $10,000 / \mathrm{cm}^{2}$ (CAPAN-2) on Petri dishes and cultured for two days $\left(37^{\circ} \mathrm{C}, 5 \%\right.$ $\mathrm{CO}_{2}$ ) in DMEM (MIAPaCa-2 and PaTu-8902 and Panc-1) or McCoy (CAPAN-2) culture medium supplemented with 10\% FBS. After two days, culture medium was replaced with appropriate DMEM (MIAPaCa-2, PaTu-8902 and Panc-1) or McCoy (CAPAN2) $\mathrm{CAF}-$ or HF-derived conditioned media. Cells were lysed after 48 and $120 \mathrm{~h}$ of cultivation in the conditioned media. Standard cultivation medium was used as control.

Effect of conditioned media on colony formation of PDAC cell lines. We tested the influence of fibroblast-conditioned media on the capacity of PDAC cell lines to produce colonies. Clonogenic assay (32) evaluates the number of proliferating colonies of cells, where a colony is defined as a group of at least 50 cells. Before the treatment, cells were seeded at a very low density of 100 cells $/ \mathrm{cm}^{2}$. Next day, the medium was replaced by either standard cultivation medium, or by the fibroblast-conditioned medium. The media were changed every $72 \mathrm{~h}$ and the culture was maintained for two weeks under standard conditions $\left(37^{\circ} \mathrm{C}, 5 \% \mathrm{CO}_{2}\right.$, humidified atmosphere). Colonies were then fixed with ethanol $(70.0 \% \mathrm{v} / \mathrm{v})$, stained with crystal violet $(0.5 \% \mathrm{w} / \mathrm{v})$ and evaluated using a stereomicroscope to establish minimally sized colonies. The whole-well images were taken on a LED transilluminator using a Universal Imagel hood (Gel Company, Inc., San Francisco, CA, USA). The number and size of the colonies were analyzed using the ImageJ software; the thresholding was based on minimal confirmed colonies.

Western blot analysis. Protein lysates were prepared as follows: initially, cells were washed with PBS, scratched, and collected in Laemmli sample buffer (100 mM TRIS-HCL, 10\% glycerol, 2\% SDS, $\mathrm{pH} \sim 6.8$ ) containing protease and phosphatase inhibitors (SigmaAldrich). Afterwards, cells were disintegrated using a sonicator (QSonica, 40\% amplitude, $15 \mathrm{~s}$ ) and centrifuged (10,000 g, $10 \mathrm{~min}$ ).
Finally, protein concentration and purity in the prepared lysates were measured using a nanophotometer (Implen).

Western blot was performed as follows: after a quick boiling step $\left(95^{\circ} \mathrm{C}, 5 \mathrm{~min}\right)$, samples were loaded into SDS-PAGE gel (10\% BisTris). Following separation, proteins were transferred to PVDF membrane using the iBlot 2 dry blotting system (Thermo Fisher Scientific). Afterwards, membranes were blocked for $1 \mathrm{~h}$ in $5 \%$ NFDM (non-fat dry milk) or BSA (bovine serum albumin) dissolved in TBS (tris-buffered saline) with $0.1 \%$ Tween at room temperature (RT). The blocking step was followed by overnight incubation with primary antibody at $4^{\circ} \mathrm{C}$. Next day, the unconjugated primary antibody was washed and the membranes were incubated with HRPconjugated secondary antibody for $1 \mathrm{~h}$ at RT. Afterwards, ECL (SuperSignal West Pico PLUS chemiluminescent Substrate, Thermo Fisher Scientific) was used to detect signal from HRP on immunoblots, which was acquired at MF-ChemiBis 2.0 (DNR BioImaging Systems). To assess even sample loading on the SDS-PAGE gel, detection of $\beta$-actin was performed. The list of used antibodies for western blot analysis is summarized in Table II.

IF of cultured cells. For immunofluorescent imaging, cells were cultivated on glass cover slips. Briefly, cells were fixed in $2 \%$ buffered paraformaldehyde $(\mathrm{pH}=7.2)$, washed with $\mathrm{PBS}$ and permeabilized with $0.1 \%$ Triton $\mathrm{X}-100$ (Sigma-Aldrich). Nonspecific binding of secondary antibodies was blocked by preincubation of samples in porcine serum albumin (DAKO, Glostrup, Denmark). Commercial primary and secondary antibodies were diluted as recommended by the suppliers. The list of used antibodies is shown in Table III. Controls of specificity were performed by replacing the primary antibody by an irrelevant antibody of the same isotype under otherwise identical conditions. Cell nuclei were counterstained with 4',6-diamidino-2-phenylindole dihydrochloride (DAPI, Sigma-Aldrich). All specimens were mounted to Vectashield (Vector Laboratories, Burlingame, CA, USA) and inspected by an Eclipse 90i fluorescence microscope (Nikon, Tokyo, Japan) 
Table III. List of antibodies employed for immunofluorescence and immuno-cyto/histo-chemistry.

\begin{tabular}{|c|c|c|c|c|}
\hline Primary antibody & Host & Clonality & Produced by & Secondary antibody \\
\hline Keratin 19 & Mouse & Monoclonal & Dako, Glostrup, Denmark & $\begin{array}{l}\text { Goat anti-mouse (TRITC conjugated), } \\
\text { Sigma-Aldrich, St. Louis, MO, USA }\end{array}$ \\
\hline Keratin 17 & Mouse & Monoclonal & Sigma-Aldrich, St. Louis, MO, USA & \\
\hline HMB45 & Mouse & Monoclonal & Invitrogen & \\
\hline Ki67 & Mouse & Monoclonal & Dako, Glostrup, Denmark & \\
\hline Melan-A & Mouse & Monoclonal & Dako, Glostrup, Denmark & \\
\hline Smooth muscle actin & Mouse & Monoclonal & Dako, Glostrup, Denmark & \\
\hline CD34 & Mouse & Monoclonal & Dako, Glostrup, Denmark & \\
\hline $\mathrm{CD} 45$ & Mouse & Monoclonal & Dako, Glostrup, Denmark & \\
\hline Vimentin & Mouse & Monoclonal & Dako, Glostrup, Denmark & \\
\hline Keratins (wide spectrum) & Rabbit & Polyclonal & Abcam, Cambridge, UK & $\begin{array}{c}\text { Swine anti-rabbit (FITC conjugated), } \\
\text { Dako, Glostrup, Denmark }\end{array}$ \\
\hline Nestin & Rabbit & Polyclonal & Sigma-Aldrich, St. Louis, MO, USA & \\
\hline Fibronectin & Rabbit & Polyclonal & Dako, Glostrup, Denmark & \\
\hline Keratin 8 & Rabbit & Polyclonal & Sigma-Aldrich, St. Louis, MO, USA & \\
\hline Vimentin & Rabbit & Polyclonal & Abcam, Cambridge, UK & \\
\hline VEGFA & Mouse & Monoclonal & R\&D System & $\begin{array}{c}\text { Goat anti-mouse/rabbit Histonfine } \\
\text { Simple Stain MAX PO, Nichirei } \\
\text { Biosciences, Tokyo, Japan }\end{array}$ \\
\hline VEGFAR 1 & Rabbit & Polyclonal & Abcam, Cambridge, UK & \\
\hline VEGFAR2 & Rabbit & Monoclonal & Cell Signaling & \\
\hline IL6 & Mouse & Monoclonal & Abcam, Cambridge, UK & \\
\hline IL6R & Rabbit & Polyclonal & Abcam, Cambridge, UK & \\
\hline IL8 & Mouse & Monoclonal & R\&D System, Minneapolis, MN, USA & \\
\hline IL8R1 & Mouse & Monoclonal & R\&D System, Minneapolis, MN, USA & \\
\hline IL8R2 & Mouse & Monoclonal & R\&D System, Minneapolis, MN, USA & \\
\hline MFGE8 & Mouse & Monoclonal & Exbio Antibodies, Vestec, Czech Republic & \\
\hline Keratin 7 & Mouse & Monoclonal & Abcam, Cambridge, UK & \\
\hline
\end{tabular}

HMB45: Melanoma marker antibody; IL: interleukin; VEGFAR: vascular endothelial growth factor A receptor.

equipped with filter blocks for FITC, TRITC, DAPI and Cool1300Q CCD camera (Vosskühler, Osnabrück, Germany). Image data were analyzed using the LUCIA 5.1 computer-assisted image analysis system (Laboratory Imaging, Prague, Czech Republic).

IHC of cultured cells and tissues. For bright-field imaging, cells were seeded on Leica X-tra slides (3800050, Leica, Tokyo, Japan) with a positively charged surface at a density of $7,500 \mathrm{cells} / \mathrm{cm}^{2}$ and cultivated overnight. In parallel, formaldehyde-fixed paraffinembedded tissues were routinely sectioned $(5 \mu \mathrm{m})$ and dried on positively charged eXtra slides (Leica). The tissue sections were then deparaffinized and rehydrated. The endogenous activity in cells/tissue sections was quenched by $1 \%$ hydrogen peroxide at room temperature for $20 \mathrm{~min}$. To avoid non-specific antibody binding, we applied Universal IHC Blocking/Diluent (Leica) for 1 hour. The primary antibodies (listed in Table III) were diluted in Antibody Diluent, Dako REAL (S-2022, DAKO) and incubated overnight at $4^{\circ} \mathrm{C}$. After rinsing in running water, the secondary antibody was applied (Histofine ${ }^{\circledR}$ Simple Stain ${ }^{\mathrm{TM}}$ MAX PO (MULTI) (Nichirei Biosciences, Tokyo, Japan) and incubated for $20 \mathrm{~min}$ at room temperature. The sections were washed in running water and incubated in N-Histofine Simple Stain AEC (415182F, Nichirei) until the development of the red-colored product was apparent under a microscope (approximately 10 minutes). The sections were then counterstained with Hematoxylin Solution, Gill No. 1 (GHS116, Sigma-Aldrich) for $3 \mathrm{~min}$ and mounted in Hydromount (HS-106, National Diagnostics, Leicestershire, UK). Negative controls were performed by replacement of primary antibody by Mouse/Rabbit Antibody Isotype Controls (08-6599 and 08-6199, Invitrogen, Carslbad, CA, USA) under otherwise identical conditions.

ELISA - Detection of IL6, IL8 and MFGE8 in culture media. Production of IL6 (EI1006-1, BioVendor, Brno, Czech Republic), IL8 (EI1008-1, BioVendor) and MFGE8 (DFGE80, R\&D Systems, Minneapolis, MN, USA) to the cultivation medium was measured by ELISA according to the manufacturer`s instructions in all tested PDAC cell lines and fibroblasts (HF/PANF). The technical duplicates were measured in 96-well plates at $570 \mathrm{~nm}$ in Universal Microplate Reader EL 800 (BIO-TEK Instruments, Winooski, VT, USA). In addition, the effect of HF/PANF-derived conditioned media on the production of IL6, IL8 and MFGE8 by PDAC cell lines was evaluated as the relative production factor (RP) defined according to the formula:

\section{$\mathrm{RP}=(\mathrm{PDAC}$ in $\mathrm{CM}-\mathrm{CM}) / \mathrm{PDAC}(\mathrm{i})$,}

where PDAC in CM is the amount of the factor produced by cancer cells cultured in the conditioned medium in pg; $\mathrm{CM}$ is the amount 
of the factor in the conditioned medium in pg; PDAC is the amount of the factor produced by cancer cells in a standard medium in pg. The value $\mathrm{RP}=1$ corresponds to no change in production of the factor, values $\mathrm{RP}>1$ indicate increased production of the factor. Whole-genome transcriptome profiling. The cells of each fibroblast population were seeded at a density of 1,000 cells $/ \mathrm{cm}^{2}$ into two (6 $\mathrm{cm}$ in diameter) Petri dishes (Corning, NY, USA) and cultured for seven days (95-100\% confluence). The culture medium was changed every two days and $24 \mathrm{~h}$ before the harvest. The cells were washed twice with PBS (Biochrom), and 350 $\mu$ RLT buffer (Qiagen, Hilden, Germany) and 2-mercaptoethanol (Sigma-Aldrich) was added. The cell lysates were collected and immediately stored at $-80^{\circ} \mathrm{C}$.

Total RNA was isolated using an RNeasy micro kit (Qiagen) according to the procedure for animal cells. The quantity and quality of RNA was analyzed using an Agilent 2100 Bioanalyzer (Agilent Technologies, Santa Clara, CA, USA). All RNA samples had RNA integrity number above 9. Total RNA (200 ng) was amplified using an Illumina TotalPrep RNA amplification kit (Ambion; Thermo Fisher Scientific, Waltham, MA, USA), and $750 \mathrm{ng}$ of the amplified RNA was hybridized on Illumina HumanHT-12 v4 chips (Illumina, San Diego, CA, USA) according to the manufacturer's protocol. The analysis was performed in three biological replicates for normal fibroblasts, eight biological replicates for the PDAC CAFs and four biological replicates for the melanoma CAFs.

The raw data was preprocessed using the GenomeStudio software (version 1.9.0.24624; Illumina) and further analyzed using the oligo (33) and limma (34) packages of Bioconductor (35). Briefly, the transcription profiles were background corrected using a normalexponential model, quantile normalized and variance stabilized using base 2 logarithmic transformation. A moderated $t$-test was used to detect differentially expressed transcripts (after fitting a linear model I group+sex). A Storey's $q$-value of $<0.05$ (36) and a minimally twofold change in expression intensity were required to consider the gene as differentially transcribed. The MIAME compliant data was deposited to the ArrayExpress database (E-MTAB-8764).

Gene set enrichment analysis (GSEA) was performed using Fisher's exact test on gene sets defined by KEGG pathways (37). Only the KEGG pathways with GSEA $p<0.0001$, a minimal overlap of ten genes and odds ratio $>2$ were considered to be statistically significant.

Statistical analysis. Statistical analysis was performed in the $\mathrm{R}$ statistical environment (https://www.r-project.org) unless stated otherwise. Multiple testing adjustment was done by the Storey's procedure ( $q$-value). Statistical analysis of the size and number of colonies was performed by one-way analysis of variance (ANOVA) followed by Tukey's post-hoc test. Statistical analysis was performed using the Past3 3.x software (38).

\section{Results}

Size and number of PDAC cell line colonies under the influence of fibroblasts. We first evaluated whether $\mathrm{HF} / \mathrm{CAF}$-conditioned media modulate the numbers and sizes of colonies in the studied PDAC cell lines. The results demonstrated that the effect of conditioned media was cellline dependent, but in six out of eight studied cases, positive influence prevailed (Figure 1A-H). In detail, the $\mathrm{HF}-$ conditioned medium stimulated the size of colonies and the number of colonies in all studied cell lines except CAPAN2 cells and MIAPaCa-2/PaTu-8902 cells, respectively (Figure 1A-C, E, H). Both tested primary cultures of PANF (P10-PANF and P11-PANF) stimulated the size (Figure 1A, $\mathrm{B}$ and $\mathrm{D}$ ) and the number of colonies (Figure $1 \mathrm{E}$ and $\mathrm{H}$ ) in the studied cancer cell lines. However, only in Panc-1 cells the effect of PANFs was higher than the effect of normal HFs (Figure 1A and E).

Western blot analysis of PDAC cell lines under the influence of fibroblasts. At the protein level, we used WB to reveal the keratin-related differentiation pattern and the status of epithelial-to-mesenchymal transition of PDAC cell lines cultured under the influence of conditioned media harvested from HFs/PANFs for 48 and $120 \mathrm{~h}$, respectively (Figure 2). The keratin panel revealed most remarkable differences in the expression of keratin 8 between the treatment conditions and cell lines, while the expression of keratins 14 and 19 remained rather stable. In detail, conditioned media induced keratin 8 upregulation in Panc-1 and CAPAN-2 cells (only after $48 \mathrm{~h}$ ) as well as slight down-regulation in MIAPaCa- 2 cells. Of note, an unchanged level of the protein was seen in PaTu-8902 cells.

Analysis of markers associated with epithelial-tomesenchymal transition (Slug, Snail, and $\mathrm{E}$ to $\mathrm{N}$ cadherin switch) showed differing behavior in the studied cell lines. Panc-1 and MIAPaCa- 2 cell lines expressed higher amounts of N-cadherin, decreased levels of E-cadherin as well as Snail up-regulation most notably after $120 \mathrm{~h}$. In contrast, CAPAN-2 cells showed minimal changes in Snail and Slug expression. Furthermore, $120 \mathrm{~h}$ cultivation resulted in stimulated epithelial polarization characterized by higher amounts of E-cadherin and lack of N-cadherin. Lastly, PaTu-8902 cells were not affected by the conditioned media.

IF analysis of PDAC under the influence of fibroblasts. The basic phenotypic changes of cancer cell lines cultivated 120 $\mathrm{h}$ under the influence of a conditioned medium harvested from HFs/PANFs were verified by immunophenotyping using a panel of standard markers. Based on the in vitro observation, the PDAC cell lines can be divided into two categories: Panc-1 and MIAPaCa-2 (Figure 3) formed large monolayer colonies, whereas CAPAN-2 and PaTu-8902 (Figure 4) formed rather small colonies with a tendency to form multi-layers.

The immunophenotype analysis revealed moderate expression of keratin 8 in Panc- 1 and MIAPaCa- 2 cell lines grown in normal culture medium (Figure 3A, E, I, M, Q, and $\mathrm{U})$, whereas added conditioned media slightly modulated its expression (Figure 3F-H, R-T). Similar levels of keratin 8 were also present in PaTu-8902 and CAPAN-2 control cultures (Figure 4A, E, I, M, Q, and U). However, in PaTu8902 cells (Figure 4F-H), the expression remained rather stable and in CAPAN-2 cells (Figure 4R-T), a slight decrease 


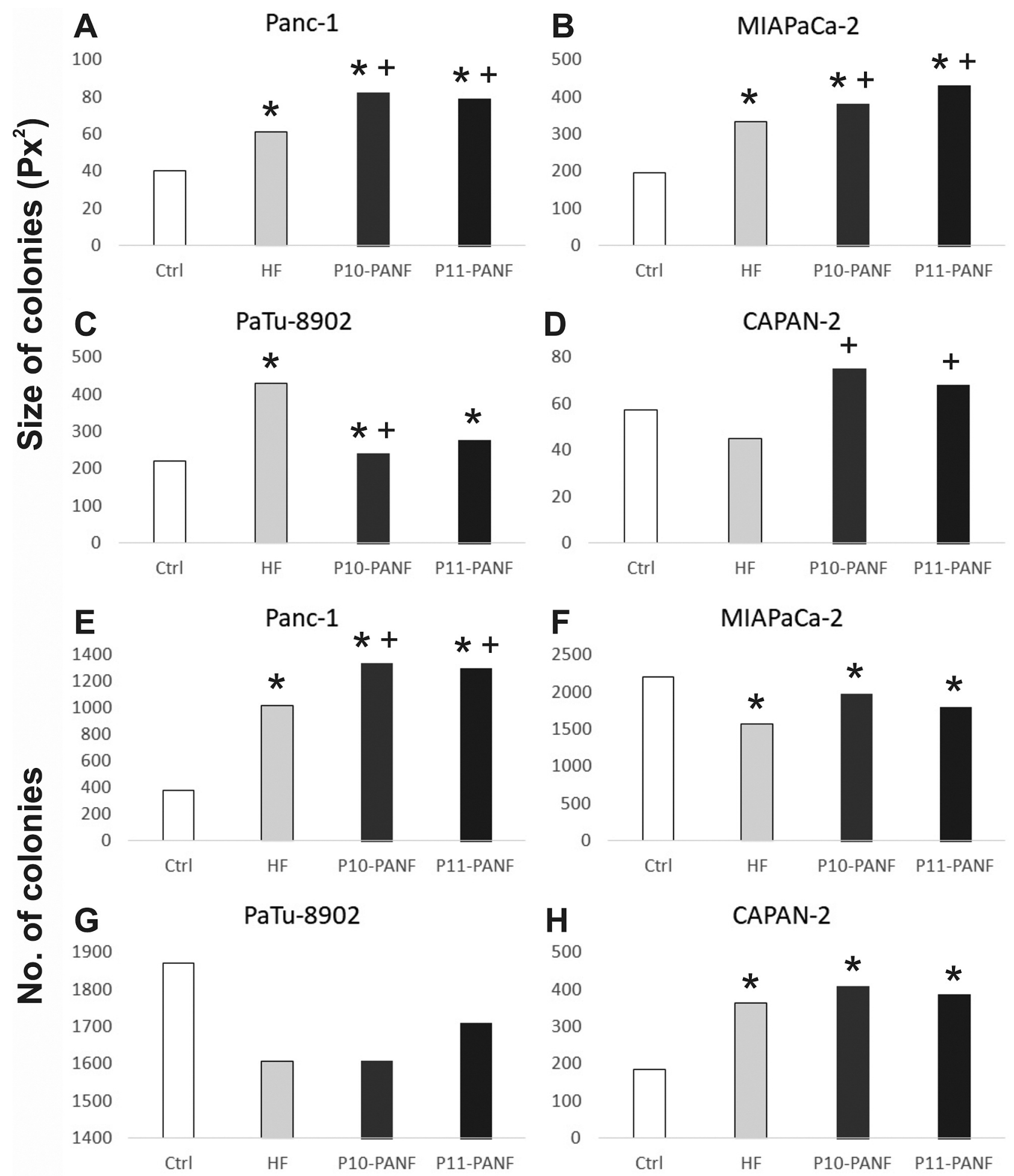

Figure 1. PANF-derived (patients P10 and P11) conditioned media positively modulated the size of colonies in Panc-1 (A), MIAPaCa-2 (B) and CAPAN-2 (D) cells, but not in PaTu-8902 cells (C). Conditioned media harvested from HFs increased the size of colonies in Panc-1 (A), MIAPaCa2 (B) and PaTu-8902 (C) cells. In CAPAN-2 cells, the HF-derived medium slightly decreased the size of colonies (D). Furthermore, the numbers of Panc-1 and CAPAN-2 colonies under the influence of PANF/HF-harvested cell-free medium were higher in comparison to the control (E, $H$ ), but only in Panc-1 cell line the effect of CAF-derived medium was higher than the effect of HF-derived medium (E). Inhibition activities of tested conditioned media were noted in MIAPaCa-2 and PaTu-8902 cell lines $(F, G)$. The level of statistical significance at $p<0.05$ is marked with asterisk $(*)$ and plus (+) for the comparison to control medium and HF-derived conditioned medium, respectively. 

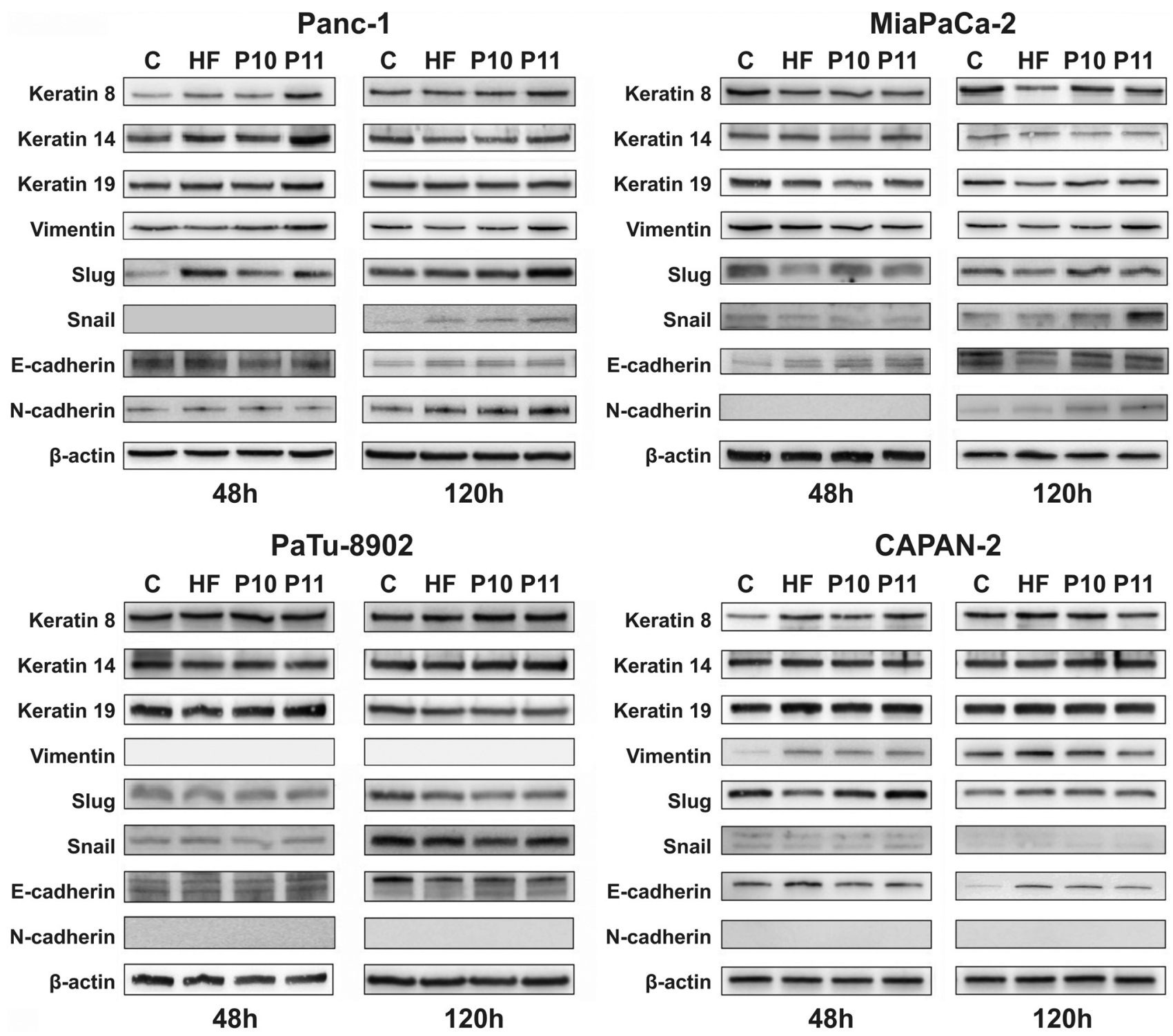

Figure 2. Differentiation pattern of the studied PDAC cell lines under the influence of conditioned media for 48 and $120 \mathrm{~h}$ derived from normal dermal fibroblasts (HFs) and PANFs (patients P10 and P11).

of keratin 8 was seen following treatment with conditioned media. On the other hand, keratin 19 was expressed rather stable in all settings (Figure 3A-D and 4M-P). Moreover, Panc-1 and MiaPaCa-2 cells expressed vimentin. Contrary, vimentin expression in CAPAN-2 cells was remarkably lower (in particular at day 2) whereas PaTu-8902 did not express vimentin at all (Figures 3I-L and 4U-X, Table IV).

Microscopic comparison of PDAC cell lines and ascitic cell primary cultures. To explain the heterogeneous pattern of the observed PDAC crosstalk at the in vitro level, we further compared the immuno-cyto/histo-chemical phenotype of primary cultures of cells derived from ascitic fluid to the tested PDAC cell lines (Figure 5A-F and Table V). The analysis revealed that only the Panc- 1 cells were positive for all tested markers (Figure 5A). Individual variability was observed in other studied cell lines and ascitic fluid primary cultures. In particular, the expression of IL8 and its receptors differed among cell lines. Weak MFGE8 signal was detected only in ascitic cells. Ascitic cells also expressed keratins 7, 8, 19 and vimentin (Figure 5E-F and Table V).

Histopathology PDAC tumor samples. We also compared the phenotype of primary cultures of ascitic cells from PDAC 


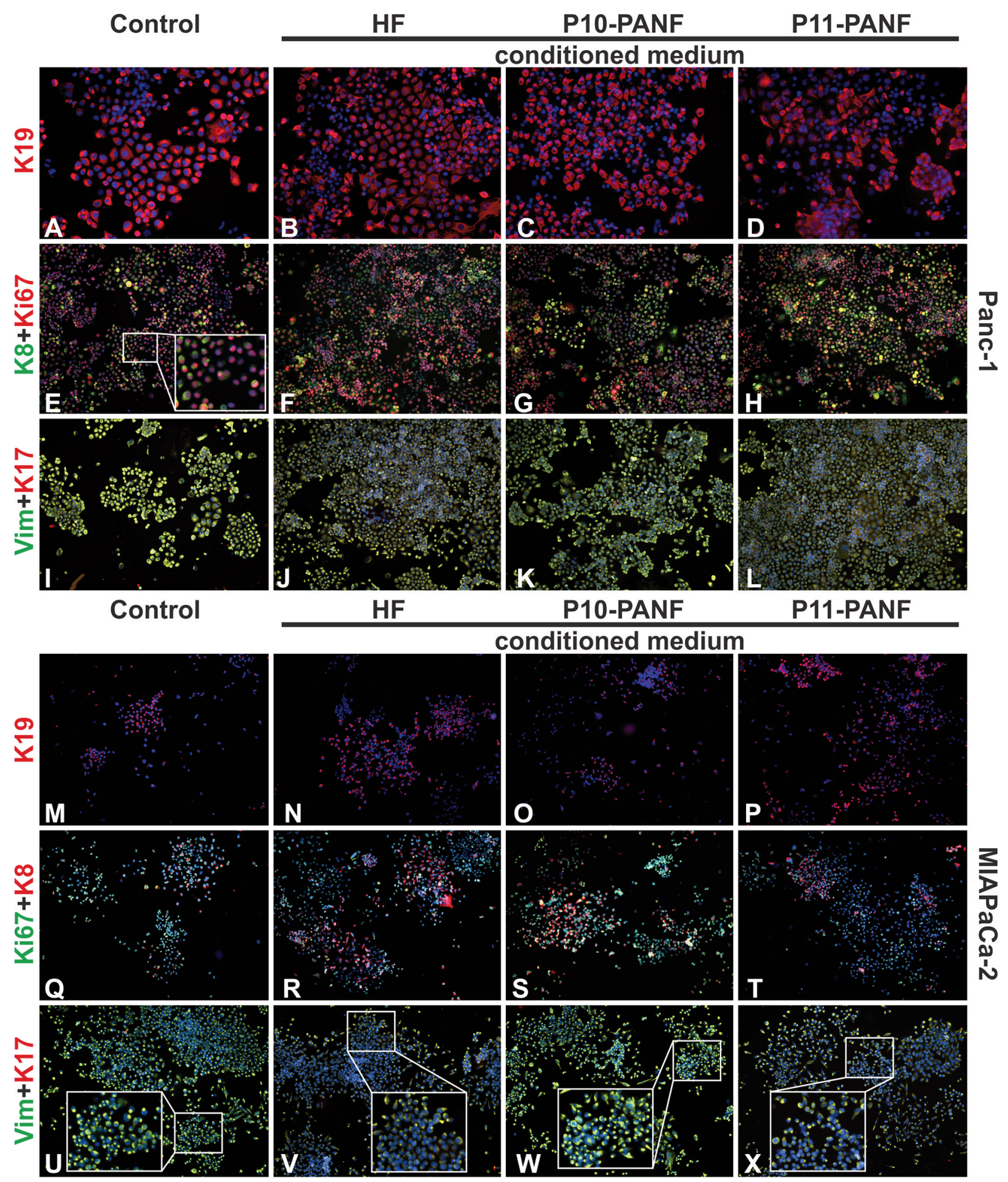

Figure 3. Immunocytochemical characterization of the studied cancer cell lines in HF/PANF-derived conditioned media: no remarkable changes were seen in the expression of keratins 19 (K19, red signal; A-D), 8 (K8, green signal; E-H) and proliferation marker Ki67 (red signal; E-H) and keratin 17 (K17, red signal; I-L) after monolayer colonies of Panc-1 cancer cell line were treated with conditioned media harvested from HFs/PANFs. Expression of vimentin was rather slightly decreased following cell treatment with conditioned media (Vim, green signal; I-L). The MIAPaCa-2 cancer cell line demonstrated a similar expression pattern as Panc-1 cells with no changes in the expression of keratin 19 (K19; red signal; M-P), keratin 8 (K8, red signal; Q-T), Ki67 (Ki67, green signal; Q-T) and keratin 17 (K17, red signal; U-X). Expression of vimentin was rather slightly decreased in all conditioned cells (Vim, green signal; $V-X)$ when compared to the control (Vim, green signal; U). 


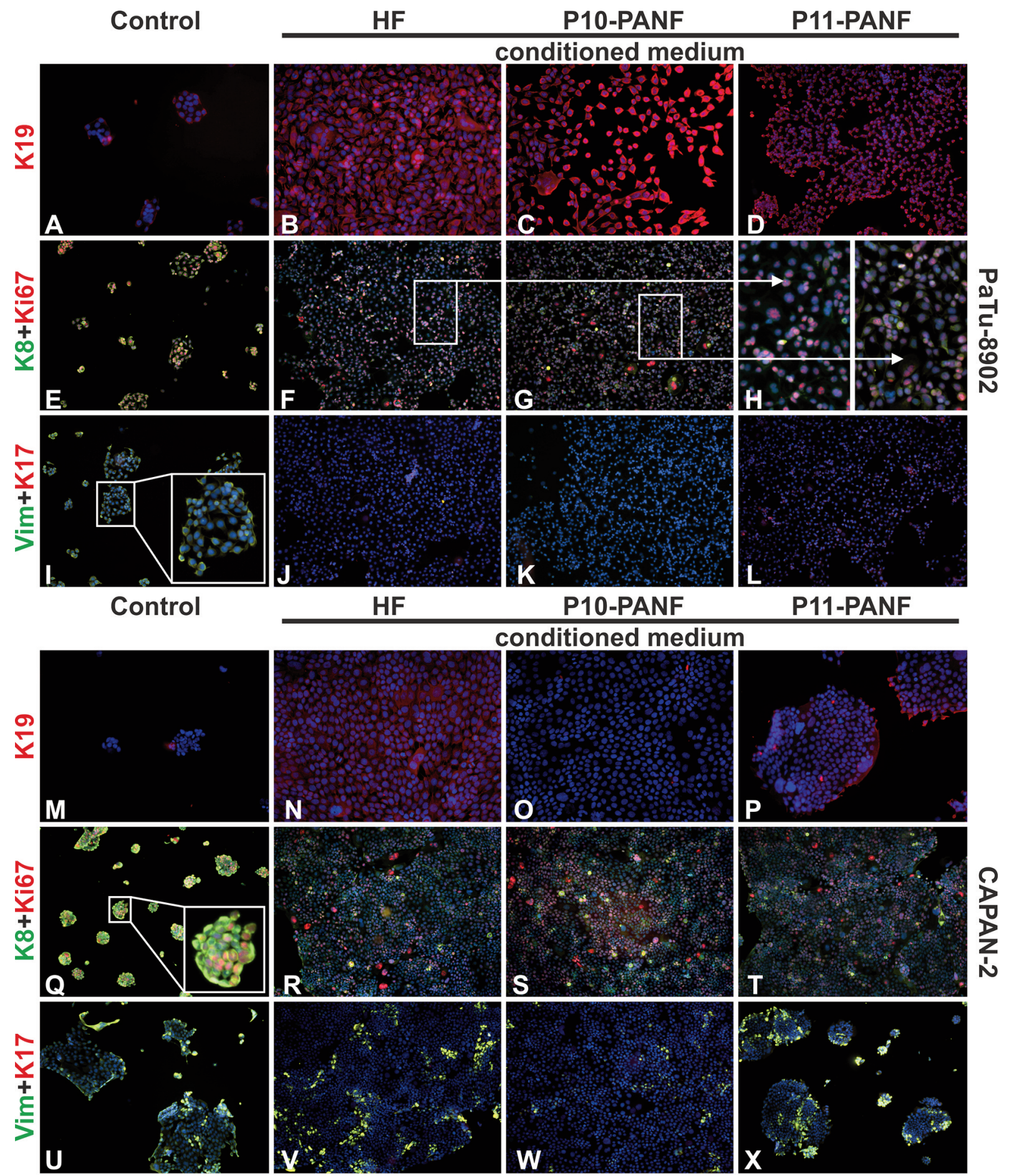

Figure 4. Immunocytochemical characterization of the studied cancer cell lines in HF/PANF-derived conditioned media: conditioned colonies of PaTu-8902 PDAC cancer cell line expressed keratin 19 (K19; red signal; A-D), but lost expression of keratin 8 (K8, green signal; F-H) and vimentin (Vim, green signal; J-L) when compared to the controls (E, I). Expression of Ki67 (red signal; E-H) and absence of keratin 17 (K17, red signal; I$L)$ remained stable; of note, conditioned PaTu-8902 cells $(B-D, F-H, J-L)$ acquired remarkably higher proliferation rates when compared to the controls (A, E, I). HF/PANF-derived conditioned media stimulated the number of CAPAN-2 cells and increased Ki67 expression (Ki67, red signal; $Q-T)$. Keratin 19 was slightly increased only in cells treated with HF-derived conditioned media (K19; red signal; $N)$, while expression of keratin 19 in cells treated with PANF-derived conditioned media (K19; red signal; O-P) remained unchanged when compared to controls (K19; red signal; $M)$. A similar level of keratin 17 expression was observed in all conditions $(K 17$, red signal; $U-X)$. The presence of conditioned media decreased expression of keratin 8 (K8, green signal; $Q-T)$ and vimentin (Vim, green signal; $U$-X) in the CAPAN-2 cell line. 
Table IV. Phenotype of native cell lines from human pancreatic ductal carcinoma after treatment.

\begin{tabular}{|c|c|c|c|c|c|c|}
\hline \multirow[t]{2}{*}{ Cell line } & \multirow[t]{2}{*}{ Fibroblast } & \multirow[t]{2}{*}{ Cytokine } & \multicolumn{4}{|c|}{ Marker } \\
\hline & & & K8 & K17 & K19 & Vim \\
\hline \multirow[t]{7}{*}{ Panc-1 } & - & - & $-1+$ & + & +++ & +++ \\
\hline & $\mathrm{HF}$ & & $-/+$ & - & +++ & ++ \\
\hline & P10-PANF & & $-/+$ & - & +++ & ++ \\
\hline & P11-PANF & & $-1+$ & - & $-1+$ & ++ \\
\hline & - & IL6 & - & ND & +++ & - \\
\hline & & IL8 & - & ND & +++ & - \\
\hline & & MFGE8 & + & ND & +++ & - \\
\hline \multirow[t]{7}{*}{ MIAPaCa-2 } & - & - & - & - & $-/+$ & +++ \\
\hline & $\mathrm{HF}$ & & $-1+$ & - & $-1+$ & + \\
\hline & P10-PANF & & $-1+$ & - & $-1+$ & +++ \\
\hline & P11-PANF & & $-/+$ & - & $-/+$ & + \\
\hline & - & IL6 & - & $\mathrm{ND}$ & ++ & ++ \\
\hline & & IL8 & - & ND & + & ++ \\
\hline & & MFGE8 & - & ND & ++ & - \\
\hline \multirow[t]{7}{*}{ PaTu-8902 } & - & - & +++ & - & $-/+$ & +++ \\
\hline & $\mathrm{HF}$ & & - & - & +++ & - \\
\hline & P10-PANF & & - & - & +++ & - \\
\hline & P11-PANF & & - & - & +++ & - \\
\hline & - & IL6 & $-1+$ & $\mathrm{ND}$ & - & - \\
\hline & & IL8 & $-/+$ & ND & - & + \\
\hline & & MFGE8 & - & $\mathrm{ND}$ & - & - \\
\hline \multirow[t]{7}{*}{ CAPAN-2 } & - & - & +++ & - & - & $-/+++$ \\
\hline & $\mathrm{HF}$ & & $-1+$ & - & + & $-/+$ \\
\hline & P10-PANF & & $-/+$ & - & - & $-/+$ \\
\hline & P11-PANF & & $-1+$ & - & $-/+$ & $-1+$ \\
\hline & - & IL6 & $-1+$ & $\mathrm{ND}$ & ++ & $-1+$ \\
\hline & & IL8 & $-1+$ & ND & ++ & $-/+$ \\
\hline & & MFGE8 & $-/+$ & ND & ++ & $-1+$ \\
\hline
\end{tabular}

HF: Human fibroblast; IL: interleukin; K: keratin; MFGE8: milk fat globule epidermal growth factor 8 (lactadherin); ND: not determined; PANF: cancer-associated fibroblasts derived from pancreatic ductal adenocarcinoma.

patients with their primary tumor tissue removed during surgical treatment. The studied tumors exhibited typical morphological features of PDAC, characterized by infiltrative groups of cancer cells in extensive desmoplastic stroma (Figure 6A and I). The expression of IL6 and IL6R was seen in cancer cells and stroma (Figure 6B, C, J and K), while IL8 and both IL8 receptors, IL8R1 and IL8R2, were absent in eight of 11 studied tumor samples (Figure 6D, E1, E2, L, M1 and M2). Although the lack of VEGFA protein was recorded in most studied specimens (Figure 6F and N), both VEGFA receptors were observed in cancer cells and stroma (Figure 6G1, G2, O1 and O2).

Immunophenotype of PANFs. To reveal whether the expression profile of fibroblasts is associated with the observed heterogeneous crosstalk at the in vitro level, we also stained cells for basic fibroblast/CAF markers (Figure 7) and performed gene expression profiling of PDAC-derived CAFs (PANFs). In parallel, normal human dermal fibroblasts (HFs) and CAFs isolated from malignant melanoma (MELFs) were examined to complete the panel of experiments. PANFs expressed vimentin, fibronectin, $\alpha$-SMA and nestin (Figure 7A-F) whereas HFs were $\alpha$-SMA and nestin negative (data not shown). Moreover, the WB analysis revealed only poor expression of PDGFR- $\beta$ in PANFs when compared to HFs Figure 7G.

Production of IL6, IL8 and MFGE8 by PDAC cell lines and studied fibroblasts. Production of all studied factors revealed individual variability in PDAC with very low production of IL6 (Figure 8A-D). Secretion of all studied factors was timedependent in normal HFs and in CAFs (Figure 8E-G).

After $48 \mathrm{~h}$, conditioned media from all types of fibroblasts, HFs and CAFs, highly stimulated production of IL6 in all PDAC cell lines (Figure 9A-L). However, the two other studied factors, IL8 and MFGE8, were not affected by the conditioned media (Figure 9A-L). Of note, IL6, IL8 and MFGE8 positively stimulated expression of keratin 19 and inhibited expression of keratin 8 and vimentin in CAPAN-2 cells (Table IV).

Molecular analysis of CAFs prepared from PDAC. As demonstrated in the heatmap, PANFs differed from MELFs and/or HFs in the transcription activity of 1,521 genes (Figure 10). The Kyoto Encyclopedia of Genes and Genomes (KEGG) pathway analysis revealed the main differences in carcinogenesis-related pathways (Table VI). Although vimentin was expressed in all studied fibroblasts, its expression in PDAC and melanoma-derived CAFs was lower than in HFs (Figure 11A). FAP expression, normally typical of CAFs, was present in all types of fibroblasts (Figure 11B). Further differences between HFs and CAFs were seen in the transcripts of keratin 8 and 18 (Figure 11C, D), which were positive only in PDAC CAFs. Interestingly, all studied fibroblasts exhibited keratin 19 at the mRNA level (Figure 11E) but remained negative at the protein level. CAFs isolated from PDAC demonstrated remarkably higher SMA expression compared to all other studied fibroblasts (Figure 11F). Moreover, the levels of IL6, VEGFA and MFGE8 transcripts increased in CAFs compared to HFs (Figure 11G, I and J). On the other hand, the concentration of IL8 (CXCL8) was lower in PDAC CAFs than in MELF and HFs (Figure 11H). The expression of integrin and periostin was higher in all studied CAFs when compared to HFs (Figure $11 \mathrm{~K}$ and $\mathrm{L}$ ).

\section{Discussion}

In the present study, we addressed the critical role of CAFs in the PDAC biology. Using a panel of in vitro experiments we provide novel evidence that the activity of stromal fibroblasts towards the four commercially available PDAC cell lines results in an efficient tumor-stroma crosstalk. Our 


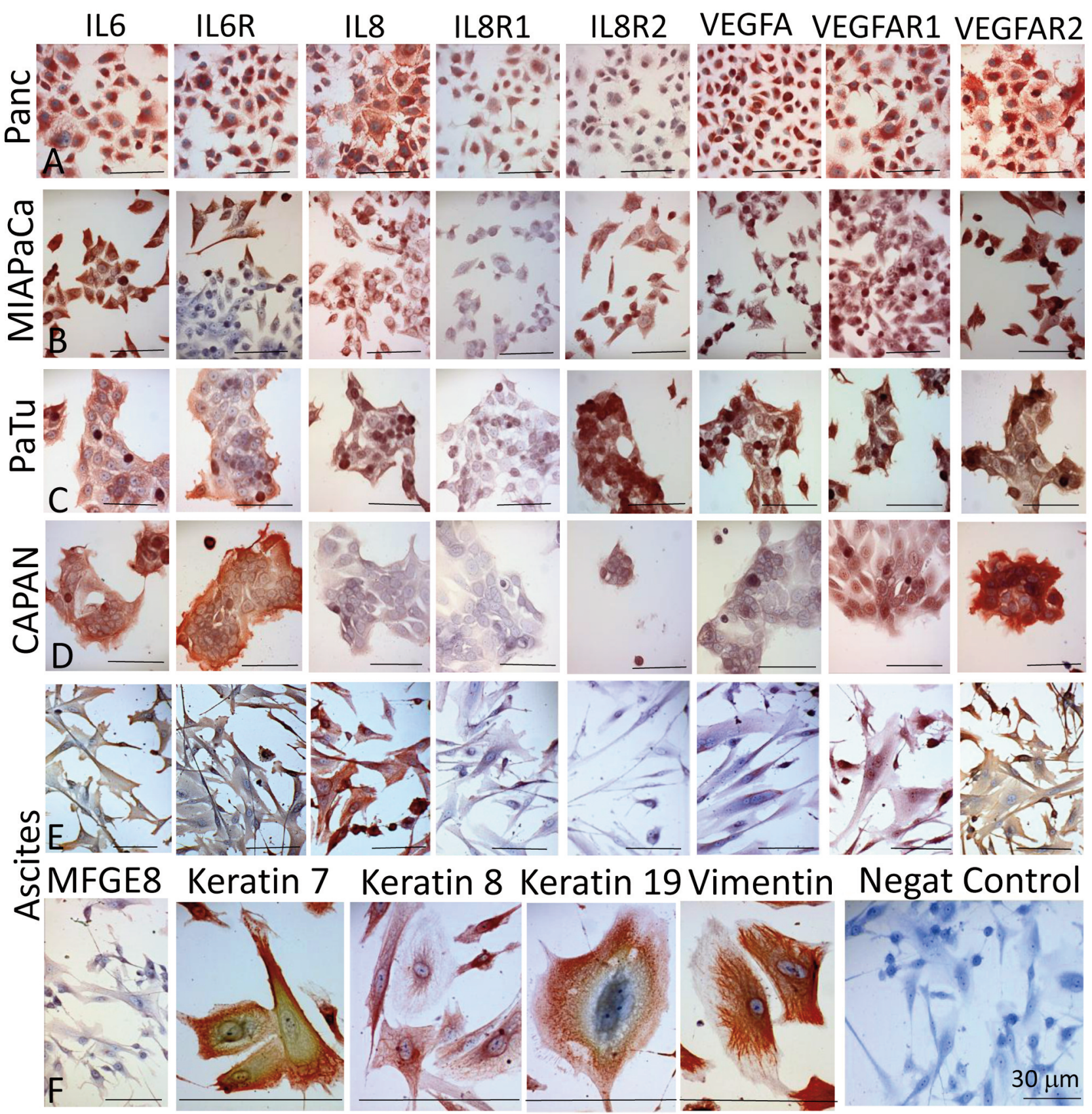

Figure 5. Comparison of PDAC cell lines and cancer cells isolated from ascitic fluid via immunocytochemical labeling of the studied molecules (IL6, IL8, VEGFA) and corresponding receptors (IL6R, IL8R1, IL8R2, VEGFAR1, VEGFAR2). All four pancreas cancer cell lines expressed VEGFA and both protein receptors VEGFARI and VEGFAR2 as well as IL6 and IL8 receptors type 2 (R2). Only the Panc-1 cell line was slightly positive for IL8R1. Lack of signals for IL6R and IL8 was demonstrated in MiaPaCa-2 and CAPAN-2 cell lines. Primary cultures from the ascetic fluid expressed keratins 7, 8, 19 and vimentin, but very weak intensity signals were recorded for IL8R1/IL8R2, VEGFA and MFGE8 (A-F).

in vitro experiments using conditioned media clearly showed certain specific differences in the growth, spread, clonogenic potential and phenotype between the four tested PDAC cells lines. In these experiments, the most aggressive behavior was acquired by Panc-1 cells (increased number and size of colonies as well as remaining expression of vimentin and keratin 8), whereas PaTu-8902 cells were rather inhibited. Of note, the conditioned media had an inverse effect on the 
Table V. Expression of selected markers in pancreatic cancer cell lines and cells isolated form ascitic fluid.

\begin{tabular}{lcccccccccccc}
\hline Cell line & IL6 & IL6R & IL8 & IL8R1 & IL8R2 & VEGFA & VEGFAR1 & VEGFAR2 & MFGE8 & VIM & K19 & K8 \\
\hline Panc-1 & +++ & +++ & +++ & ++ & ++ & +++ & +++ & +++ & + & & Data are shown in Table IV \\
MIAPaCa & +++ & - +++ & ++ & + & ++ & +++ & +++ & +++ & + & & \\
Patu-8902 & +++ & ++ & +++ & + & +++ & +++ & +++ & +++ & + & \\
CAPAN-2 & +++ & +++ & + & + & +++ & ++ & ++ & +++ & + & ND & ND & ND \\
Ascites-1 & ++ & ++ & +++ & + & + & + & +++ & +++ & + & ++ \\
Ascites-2 & +++ & ++ & +++ & + & + & + & ++ & +++ & + & +++ & +++ & ++ \\
Ascites-3 & ++ & ++ & ++ & + & + & + & ++ & ++ & ND & +++ & +++ & ++ \\
Ascites-4 & +++ & +++ & ++ & + & - & + & ++ & +++ & ND & +++ & +++ & +++ \\
\hline
\end{tabular}

IL: Interleukin; ILR: interleukin receptor; K: keratin; MFGE8: milk fat globule epidermal growth factor 8 (lactadherin); ND: not determined; VEGFA: vascular endothelial growth factor A; VEGFAR: vascular endothelial growth factor A receptor.

size and number of colonies in MIAPaCa-2 cells, whereas CAPAN-2 cells were rather stimulated (increased size and number of colonies). Markers associated with epithelial-tomesenchymal transition (Slug, Snail and $\mathrm{E}$ to $\mathrm{N}$ cadherin switch) of cells were up-regulated in Panc-1 and MiaPaCa2 cells whereas PaTu-8902 and CAPAN-2 cells were not deregulated. TGF- $\beta 1$ is perhaps the most potent EMTinducing factor secreted by CAFs $(39,40)$ activating MAPK signaling (41), which in combination with STAT3 signaling has recently been identified as critical in generating the invasive and proliferative phenotype (42). Notably, EMT may be driven in various PDAC cell lines as a response to different exogenous factors; for instance, TNF- $\alpha$ and IL- $1 \beta$ were shown to induce EMT in PaTu-8988T and AsPC-1 cells via Hedgehog signaling (43). The heterogeneous responses of PDAC cell lines to CAF-derived conditioned media in our study may, thus, reflect diverse sensitivity of PDAC cell lines to secreted soluble factors and their pre-existing cell line-specific epithelial/quasi-mesenchymal phenotype. Accordingly, heterogenous responses of cancer cell lines to stromal cells have also been indicated in numerous experimental and clinical studies (44-47). For example, depletion of SMA-positive myofibroblasts in an animal model of PDAC resulted in multiple adverse outcomes leading to poor survival (48); thus, it may be suggested that myofibroblasts rather inhibit than support the growth of PDAC, as speculated previously (49).

It has been shown that circulating levels of IL6 were significantly increased in PDAC patients (correlating with pro-tumorigenic microenvironment, cancer progression and metastatic dissemination) $(50,51)$ and that blocking of IL6 receptor in animal models enhanced efficacy of anti-PDAC chemotherapy $(52,53)$. The in vitro observed down-regulated IL6 production by CAFs resulting in inhibition of migration and epithelial-to-mesenchymal transition of Panc- 1 and Aspc-1 cells (54) supported the involvement of interleukins in cancer biology. Previously, it has been shown that simultaneous blocking of IL6 and IL8 signaling pathways infers a strategy to inhibit tumor cell migration of human melanoma and sarcoma $(55,56)$. Hence, we studied whether the combination of IL6 and IL8 is also involved in the epithelial-mesenchymal crosstalk of PDAC. To provide the answer to that question we examined tumor sections, PDAC cell lines and primary cultures derived from ascitic fluid for the presence of IL6, IL8 and their receptors. These analyses revealed a strong signal of IL6 in the tumors and in ascitic cancer cells. Nevertheless, the regulation of IL8 expression demonstrated rather an opposite pattern in terms of histology, and thus we did not observe any expression of IL8 and both its receptors in the PDAC sections. IL8 is also produced by CAFs and drives cancer cell invasiveness and tumor neovascularization $(57,58)$.

To provide further answers to the involvement of IL8 and IL6 in PDAC, we performed functional in vitro co-culture assays to study how the crosstalk modulated interleukin production into the culture medium. Although long-term culture of CAPAN-2 cells resulted in increased production of IL6 into the medium, the production in normal fibroblasts and CAFs was higher than in all studied cancer cells. However, conditioned media from long-term cultured fibroblasts contained higher concentrations of IL6 than cancer cells. This increase had, however, no effect on further increase in IL6 production by cancer cells. This observation indicates that the production of IL6 by PDAC cells is regulated by both fibroblasts and cancer cells. Interestingly, its production was stimulated by prolonged cultivation in PaTu-8902 and CAPAN-2 cells and inhibited in MIAPaCa- 2 cells. All types of fibroblasts stimulated production of IL8 to the medium in a time-dependent manner. At the mRNA level, the expression of IL8 was lower than in normal fibroblasts and CAFs from melanoma. In contrast to the IL6 profile, conditioned media derived from cultures of HFs and CAFs had no effect on the production of IL8 by cancer cells. Although serum levels of IL8 may be considered as a prognostic factor in PDAC patients (59), the expression of IL8 and its receptors was only rarely found in PDAC samples (16). 

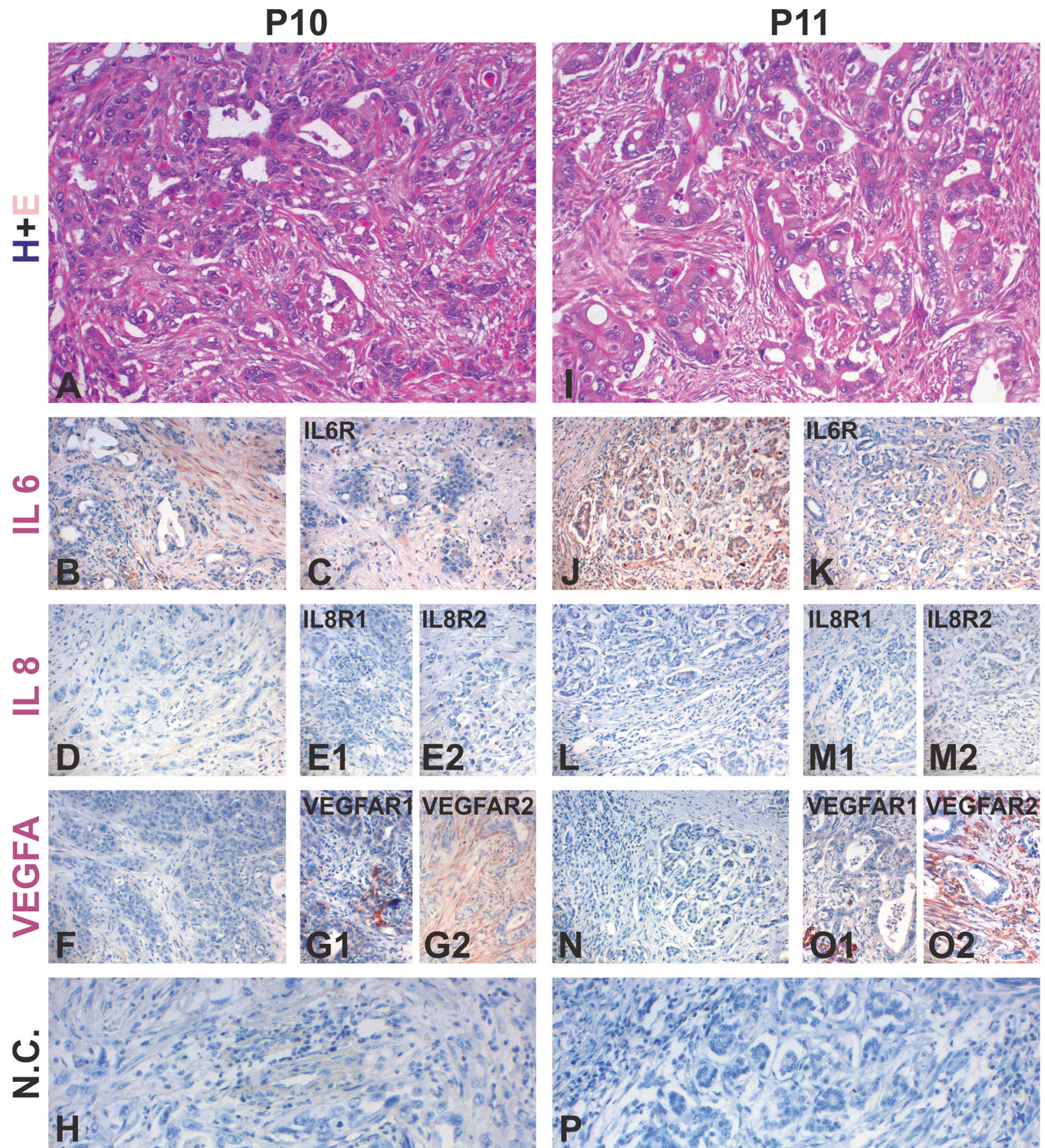

Figure 6. Basic histology $(H+E)$ and immunohistochemical analysis of paraffin-embedded tumor sections from patients (P10 and P11) with PDAC shows widespread stroma volume in both tumors $(A, I)$. Positive signal for $\operatorname{IL6}(B, J), I L 6 R(C, K), \operatorname{VEGFR1}(G 1, O 1)$ and VEGFR2 (G2, O2) was observed in cancer cells and tumor stroma. Weak expression of VEGFA was demonstrated in nine of 11 tissue samples $(F, N)$; eight of 11 tumor samples expressed neither the IL8 $(D, L)$ protein nor both its receptors, IL8R1 $(E 1, M 1)$ and IL8R2 (E2, M2). Negative control for antibody validation (H, P).

The expression profiles of CAFs clearly indicated that MFGE8/lactadherin is up-regulated when compared to normal HFs. Direct high-level secretion of the MFGE8 protein to the culture medium was observed only in the biologically most active Panc-1 cell line. Other tested PDAC cell lines secreted
MFGE8 at lower levels, but prolonged cultivation resulted in an increase of its secretion. Conditioned media derived from cultures of fibroblasts had little effect on the production of MFGE8 by cancer cells. From this point of view, MFGE8 appears to play a key role also in other cancers $(15,60,61)$, and 

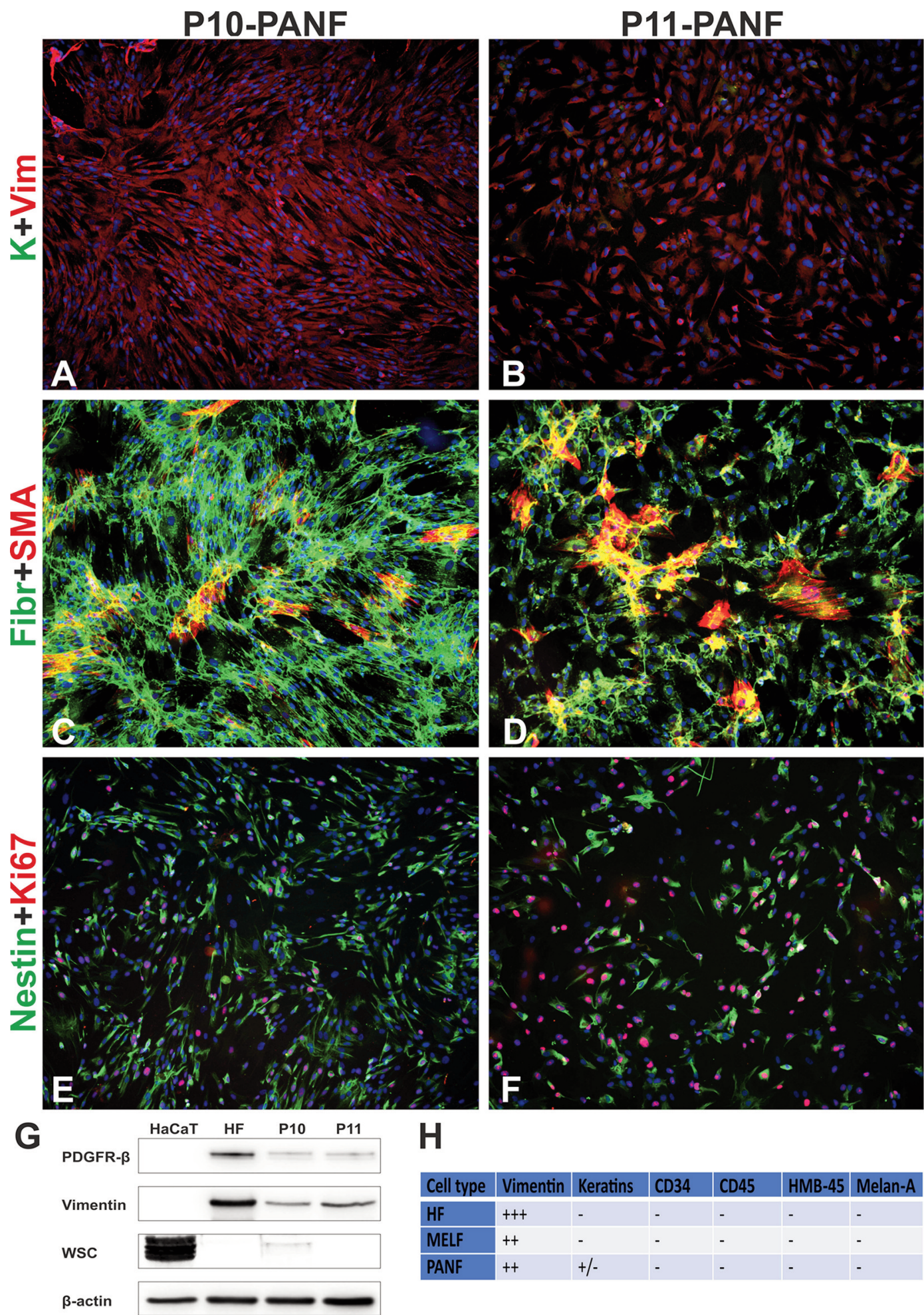

H

\begin{tabular}{|l|l|l|l|l|l|l|}
\hline Cell type & Vimentin & Keratins & CD34 & CD45 & HMB-45 & Melan-A \\
\hline HF & +++ & - & - & - & - & - \\
\hline MELF & ++ & - & - & - & - & - \\
\hline PANF & ++ & + +- & - & - & - & - \\
\hline
\end{tabular}

Figure 7. Immunofluorescent analysis of isolated primary cultures of PDAC-derived CAFs (PANFs) from patients P10 and P11. P10/P11-PANFs expressed vimentin (red signal) and were keratin negative (green signal) (A, B). Proliferation marker Ki67 (red signal; E, F), fibronectin (Fibr, green signal; $C, D)$ and $\alpha$-smooth muscle actin (SMA, red signal; $C, D)$ were also detected. Both PANFs also expressed the intermediate filament nestin (green signal; $E, F)$. Western blot $(G)$ shows expression of fibroblast-negative/positive markers (PDGFR- $\beta$ - platelet derived growth factor receptor beta; WSC - wide spectrum cytokeratin) in the used primary cultures (HaCaT keratinocytes were used as control). Table (H) summarizes immunophenotypes of the studied fibroblasts (staining for CD34, CD45, HMB45, and Melan-A is not shown). 


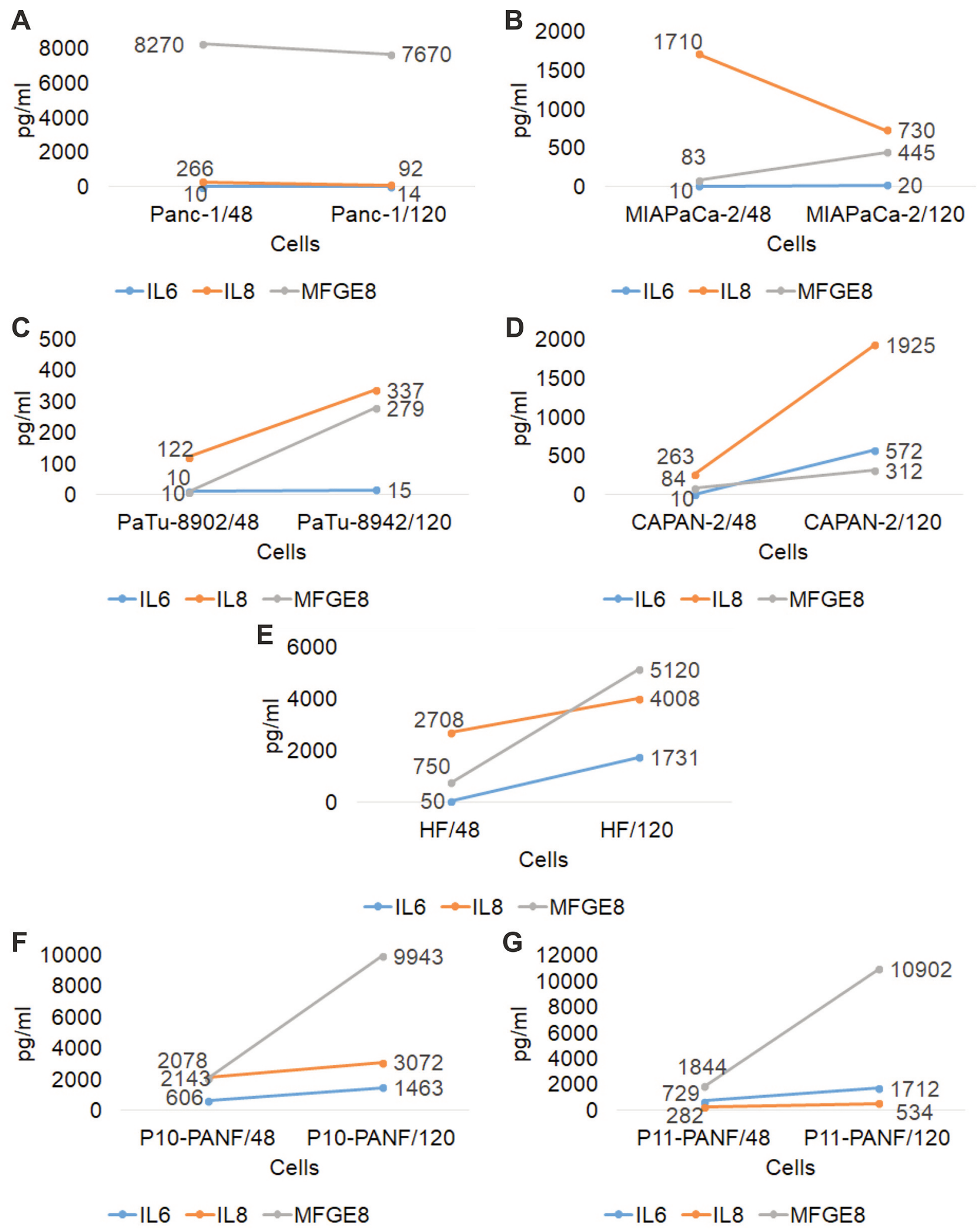

Figure 8. Measurement of MFGE8 and IL8 production revealed certain inter-cell line variability, while the IL6 protein remained rather at a low level in all studied PDAC lines (A-D). PANF/HF production of the studied protein demonstrated rather time-line-dependent production into the culture medium $(E-G)$. 

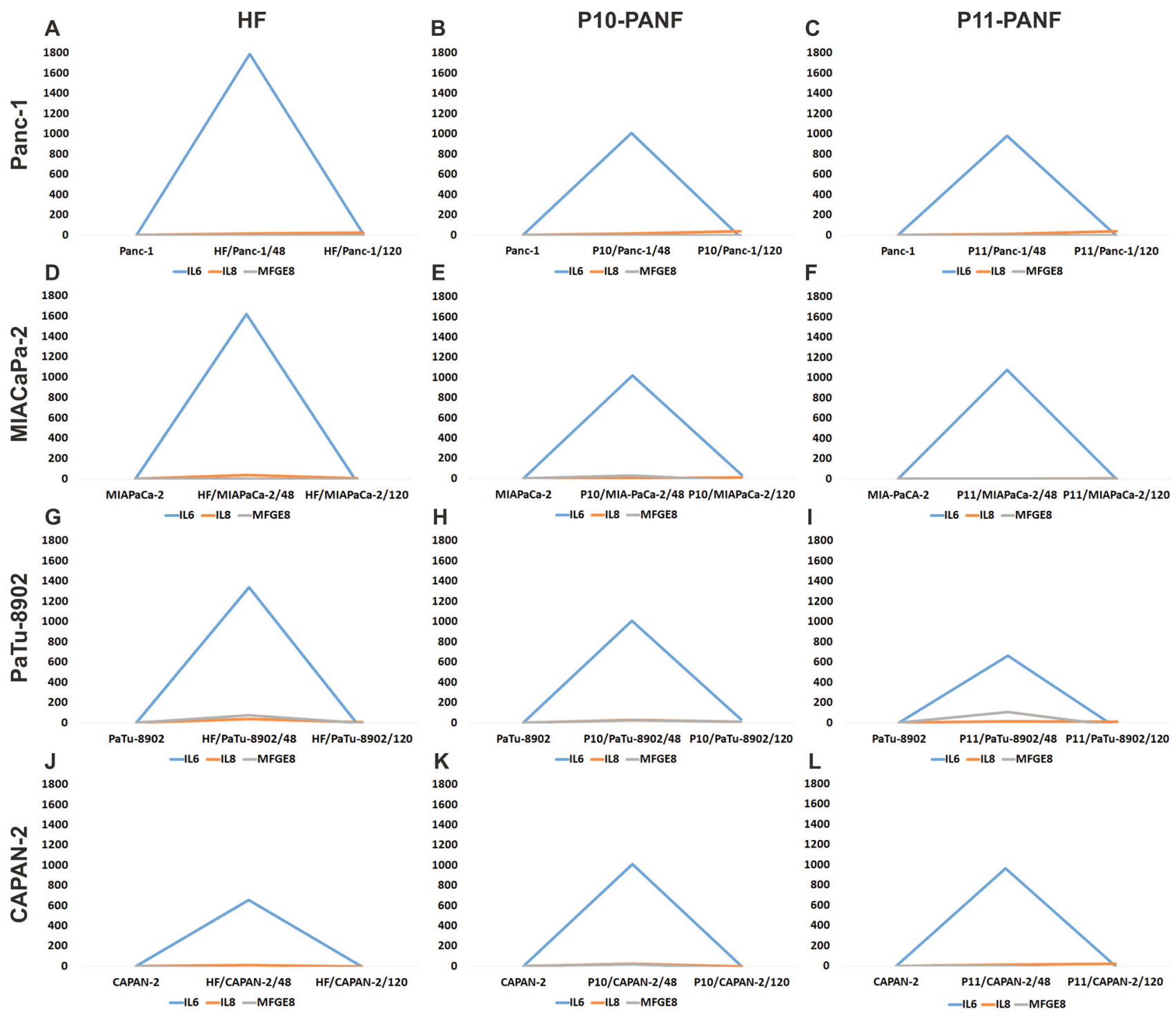

Figure 9. HF/PANF-derived conditioned media significantly induced production of IL6 in all tested PDAC cell lines after $48 \mathrm{~h}$ of cultivation (A-L). The levels of IL8 and MFGE8 remained rather stable (A-L).

thus an additional important role to its originally identified function, namely protection of the newborns against rotavirus infection (62). Even though the data from humans demonstrated its participation in the progression of acute pancreatitis (63), to our best knowledge, its involvement in PDAC in humans has remained unknown.

Comparative analysis of the expression profile of HFs and PANFs demonstrated differences in several KEGG pathways. For instance, several important cancer-regulating pathways such as TGF- $\beta$ signaling pathway, transcriptional misregulation in cancer, focal adhesion and ECM-receptor interaction pathways have been identified as dysregulated in the present study. Focusing on key cancer-related genes, we observed increased expression of periostin [angiogenesis (64) and epithelial-tomesenchymal transition (65) inducer] in the stroma of invasive PDAC (66). Furthermore, PANFs expressed very high levels of VEGF-A, a protein whose role is not limited only to angiogenesis and vascular permeability, but its signaling also occurs in tumor cells and contributes to key aspects of tumorigenesis, including the function of cancer stem cells and tumor initiation (67). We were surprised to observe the transcripts for keratins 8 and 18 in PNAFs, which was, however, not seen at the protein level. It has been shown that fibroblasts in pathological conditions may be formed rather from local fibroblasts, mesenchymal stem cells or podocytes than from epithelial cancer cells by EMT (68). However, under certain 


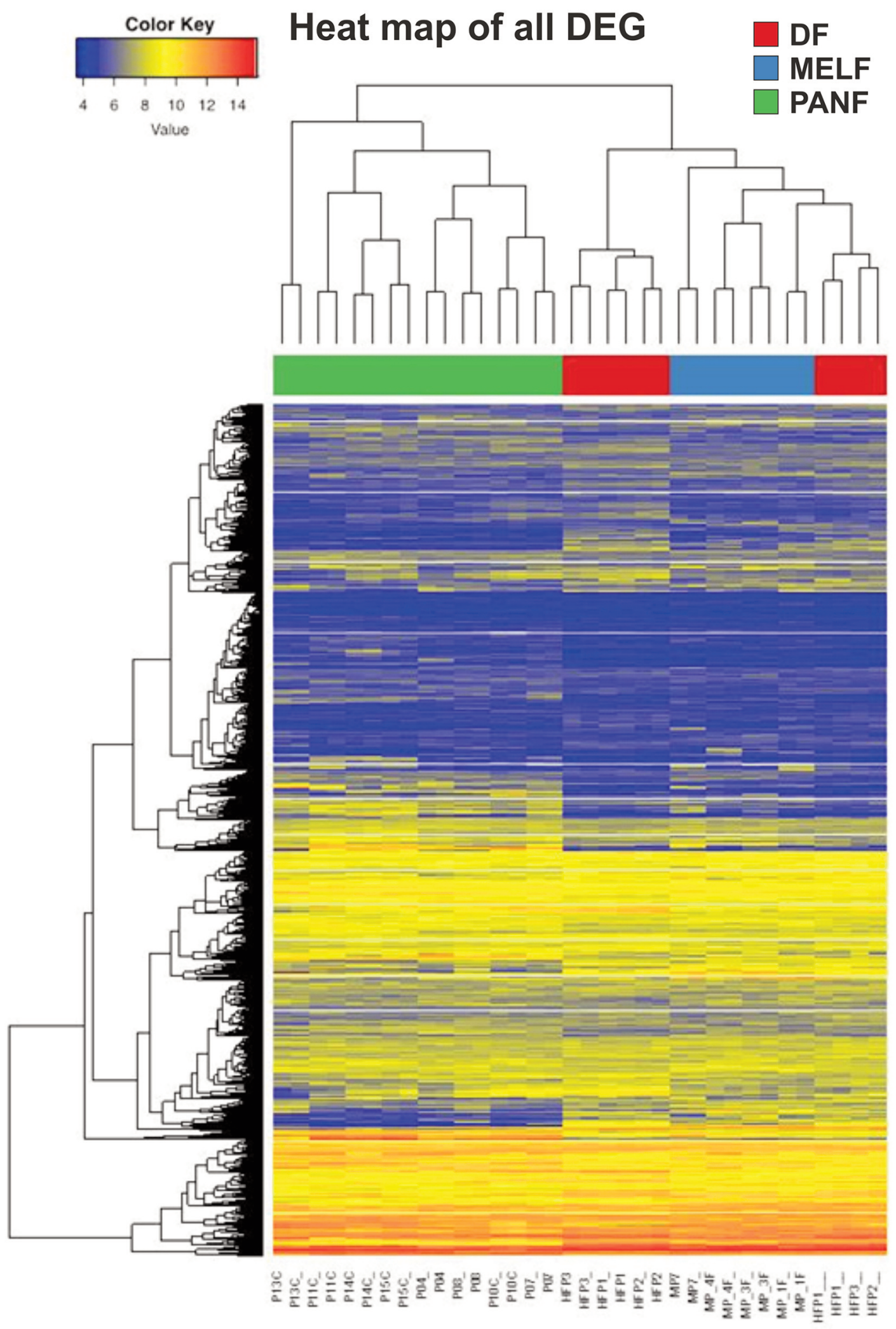

Figure 10. Cancer-associated fibroblasts (CAFs) derived from pancreatic ductal adenocarcinoma (PANF) differ in gene expression from both normal dermal fibroblasts $(H F)$ and CAFs isolated from malignant melanoma (MELF). The heat map shows expression intensities, in logarithmic scale, of 1,521 genes found to be significantly differentially expressed between PANFs, MELFs and HFs. 
Table VI. Gene set enrichment analysis (GSEA) of KEGG pathways.

\begin{tabular}{|c|c|c|c|c|c|c|}
\hline Rank & Accession & Pathway & Category size & Overlap & Odds ratio & $p$-Value \\
\hline 1 & $\begin{array}{l}\text { hsa05200 (https://www.genome.jp/ } \\
\text { kegg-bin/show_pathway?hsa05200) }\end{array}$ & Pathways in cancer & 521 & 58 & 2.168 & $4.44 \mathrm{e}-07$ \\
\hline 2 & $\begin{array}{l}\text { hsa04350 (https://www.genome.jp/ } \\
\text { kegg-bin/show_pathway?hsa04350) }\end{array}$ & TGF- $\beta$ signaling pathway & 81 & 16 & 3.848 & $2.02-\mathrm{e} 05$ \\
\hline 3 & $\begin{array}{l}\text { hsa05202 (https://www.genome.jp/ } \\
\text { kegg-bin/show_pathway?hsa05202) }\end{array}$ & $\begin{array}{c}\text { Transcriptional misregulation } \\
\text { in cancer }\end{array}$ & 178 & 25 & 2.735 & $2.57 \mathrm{e}-05$ \\
\hline 4 & $\begin{array}{l}\text { hsa04510 (https://www.genome.jp/ } \\
\text { kegg-bin/show_pathway?hsa04510) }\end{array}$ & Focal adhesion & 196 & 26 & 2.584 & $4.2 \mathrm{e}-05$ \\
\hline 5 & $\begin{array}{l}\text { Hsa04512 (https://www.genome.jp/ } \\
\text { kegg-bin/show_pathway?hsa04512) }\end{array}$ & ECM-receptor interaction & 79 & 15 & 3.698 & $5.38 \mathrm{e}-05$ \\
\hline
\end{tabular}

ECM: Extracellular matrix; TGF- $\beta$ : transforming growth factor beta.

conditions, fibroblasts and mesenchymal stem cells may also express keratins (69-73). Whether the herein observed expression profile of PANFs indicates their epithelial origin remains to be answered in further studies.

\section{Conclusion}

Our study revealed that the four tested PDAC cell lines respond to the studied fibroblasts (HFs and PANFs) differently. Among many identified important regulatory molecules, only proinflammatory cytokine IL6 seems to be uniformly regulated in our in vitro model and was found significantly increased in serum levels of PDAC patients. Further identified molecules such as IL8, periostin and MFGE8 were also critically involved in the crosstalk of the PDAC ecosystem, but their regulation/expression revealed certain variations. Our data may summarize two important aspects of PDAC biology. Firstly, PANFs are more stable than epithelial cancer cells, and thus an effective combination of anti-neoplastic drugs with genetargeted therapy should rather target the cancer stroma to be effective as a pharmacological weapon increasing the survival rates of PDAC patients. Secondly, the present study also reflects certain limitations of the tested cell lines whose biological properties do not reflect the original grade of the tumors from which they were isolated. In general, we conclude that our study supports the desmoplastic patient-specific character of cancer cell regulation by CAFs, which precludes development of an effective treatment strategy and rather requires establishment of an individualized tumor/patient-specific treatment protocol for the use in human clinical practice.

\section{Conflicts of Interest}

The Authors have no conflicts of interest to declare.

\section{Author' Contributions}

Conceptualization, Pavol Szabo; Formal analysis, Michal Kolář, Karel Smetana Jr., and Peter Gál; Funding acquisition, Karel
Smetana Jr. Michal Kolář, and Peter Gál; Investigation and methodology, Štepan Novák, Lukáš Lacina, Michal Kolář, Arpád Szabó, Zdena Vernerová, Lukáš Lacina, Hynek Strnad, Jana Šáchová, Miluše Hradilová, Jan Havránek, Michal Španko, Matus Čoma, Lukáš Urban, Miriam Kaňuchová, Robert Gurlich, Jozef Dvořák, and Pavol Szabo; Supervision, Karel Smetana Jr. and Peter Gál; Writing - original draft, Peter Gál and Pavol Szabo. All authors read and approved the final version of the manuscript.

\section{Acknowledgements}

This article is dedicated to the memory of our distinguished colleague and co-author Zdena Vernerová, who passed away in course of the preparation of this article.

This study was supported in part by the project "Centre for Tumour Ecology - Research of the Cancer Microenvironment Supporting Cancer Growth and Spread" (No. CZ.02.1.01/0.0/0.0/16_019/0000785) supported by the Operational Programme "Research, Development and Education", by Charles University in Prague (PROGRES Q28 and Q37), by the Slovak Research and Development Agency under the contracts Nos. APVV-14-0731 and APVV-16-0446, and Medical University Science Park in Košice (MediPark, Košice - Phase II) ITMS2014+ 313011D103 supported by the Operational Programme "Research and Innovations", funded by the ERDF. Authors are grateful to Dr. Šárka Takáčová for the revision of English.

\section{References}

1 Adamska A, Domenichini A and Falasca M: Pancreatic ductal adenocarcinoma: Current and evolving therapies. Int J Mol Sci 18(7): 1338, 2017. PMID: 28640192. DOI: 10.3390/ijms18071338

2 Weidle UH, Birzele F and Nopora A: Pancreatic ductal adenocarcinoma: MicroRNAs affecting tumor growth and metastasis in preclinical in vivo models. Cancer Genomics Proteomics 16(6): 451-464, 2019. PMID: 31659100. DOI: $10.21873 / \mathrm{cgp} .20149$

3 Vincent A, Herman J, Schulick R, Hruban RH and Goggins M: Pancreatic cancer. Lancet 378(9791): 607-620, 2011. PMID: 21620466. DOI: 10.1016/S0140-6736(10)62307-0

4 Foucher ED, Ghigo C, Chouaib S, Galon J, Iovanna J and Olive D: Pancreatic ductal adenocarcinoma: A strong imbalance of good and bad immunological cops in the tumor microenvironment. Front Immunol 9: 1044, 2018. PMID: 2986 8007. DOI: 10.3389/fimmu.2018.01044 

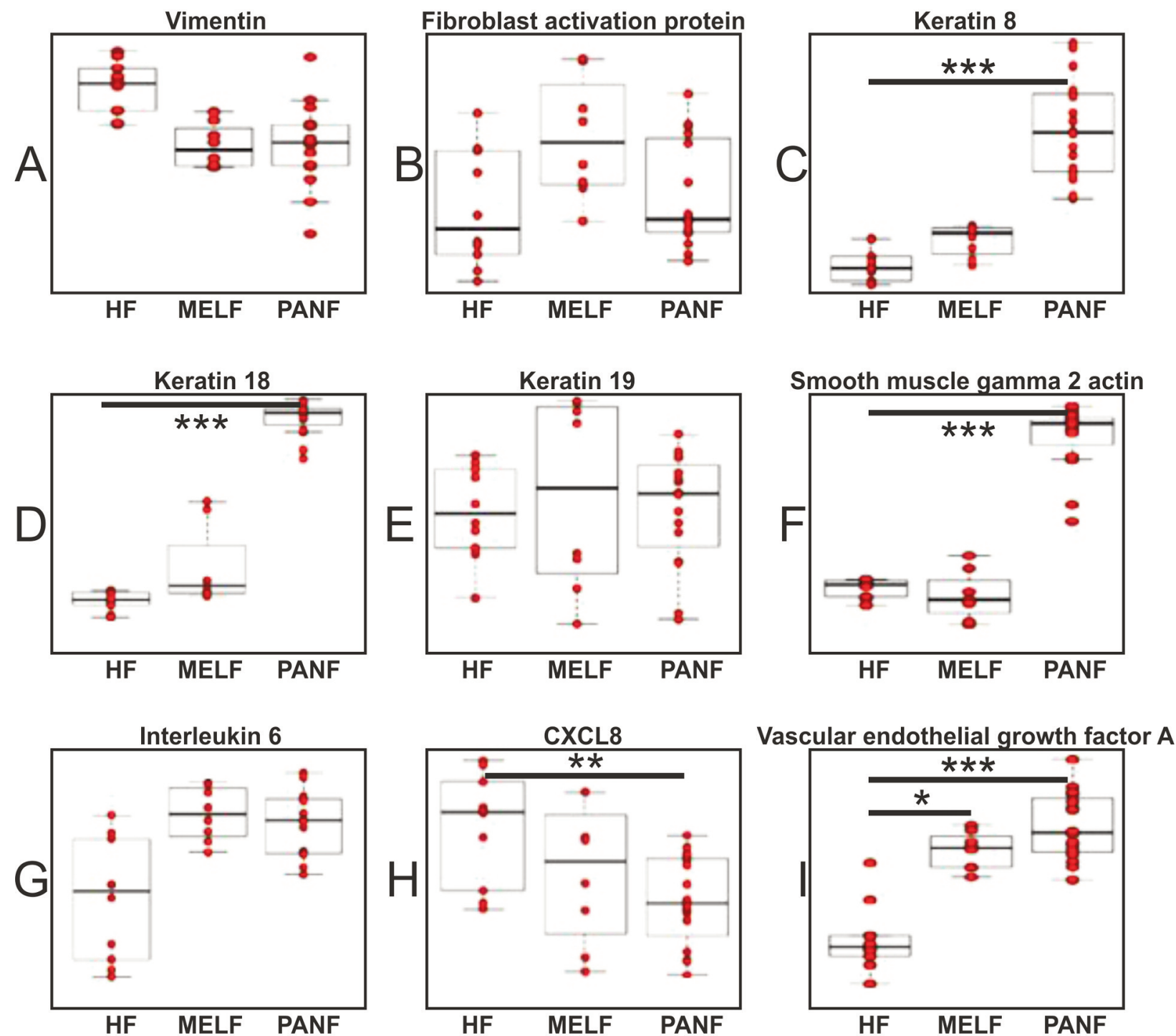

\section{Milk fat globule-EGF factor 8}
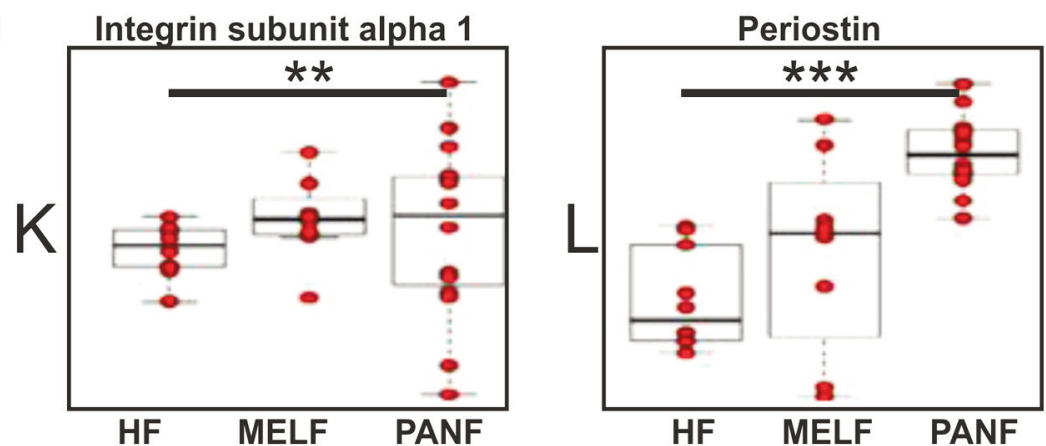

Figure 11. Examples of critical differentially expressed genes revealed in the molecular analysis when cancer-associated fibroblasts (CAFs) derived from pancreatic ductal adenocarcinoma (PANFs) were compared with normal dermal fibroblasts (HFs) and CAFs isolated from malignant melanoma (MELFs). Normal fibroblasts expressed vimentin in higher amounts than both studied CAFs (A). Interestingly, all types of fibroblasts exhibited mRNA levels of FAP and keratin 19 (B, E). PANFs demonstrated the highest transcript levels of keratins 8, 18, SMA, MFGE8 and periostin in comparison with other studied fibroblasts $(C, D, F, J, L)$. PANFs and MELFs expressed higher amounts of IL6 transcript, VEGFA and integrin $\alpha 1$ than HFs. The highest levels of IL8 mRNA was seen in HFs while the lowest in PANFs $(G-I, K)$. Asterisks mark the level of statistical significance with *, ** and *** standing for Storey's $q<0.1,0.05$ and 0.005 , respectively. 
5 Li H, Mao Y, Xiong Y, Zhao HH, Shen F, Gao X, Yang P, Liu X and $\mathrm{Fu}$ D: A comprehensive proteome analysis of Peripheral Blood Mononuclear Cells (PBMCs) to identify candidate biomarkers of pancreatic cancer. Cancer Genomics Proteomics 16(1): 81-89, 2019. PMID: 30587502. DOI: $10.21873 / \mathrm{cgp} .20114$

6 Zhang A, Qian Y, Ye Z, Chen H, Xie H, Zhou L, Shen Y and Zheng S: Cancer-associated fibroblasts promote M2 polarization of macrophages in pancreatic ductal adenocarcinoma. Cancer Med 6(2): 463-470, 2017. PMID: 28097809. DOI: 10.1002/cam4.993

7 Hruban RH, Gaida MM, Thompson E, Hong SM, Noë M, Brosens LA, Jongepier M, Offerhaus GJA and Wood LD: Why is pancreatic cancer so deadly? The pathologist's view. J Pathol 248(2): 131141, 2019. PMID: 30838636. DOI: 10.1002/path.5260

8 Burris HA 3rd, Moore MJ, Andersen J, Green MR, Rothenberg ML, Modiano MR, Cripps MC, Portenoy RK, Storniolo AM, Tarassoff P, Nelson R, Dorr FA, Stephens CD and Von Hoff DD: Improvements in survival and clinical benefit with gemcitabine as first-line therapy for patients with advanced pancreas cancer: A randomized trial. J Clin Oncol 15(6): 2403-2413, 1997. PMID: 9196156. DOI: 10.1200/JCO.1997.15.6.2403

9 Conroy T, Desseigne F, Ychou M, Bouché O, Guimbaud R, Bécouarn Y, Adenis A, Raoul JL, Gourgou-Bourgade S, de la Fouchardière $\mathrm{C}$, Bennouna $\mathrm{J}$, Bachet JB, Khemissa-Akouz F, PéréVergé D, Delbaldo C, Assenat E, Chauffert B, Michel P, MontotoGrillot C, Ducreux M, Groupe Tumeurs Digestives of Unicancer. and PRODIGE Intergroup.: FOLFIRINOX versus gemcitabine for metastatic pancreatic cancer. N Engl J Med 364(19): 1817-1825, 2011. PMID: 21561347. DOI: 10.1056/NEJMoa1011923

10 Krempley BD and Yu KH: Preclinical models of pancreatic ductal adenocarcinoma. Chin Clin Oncol 6(3): 25, 2017. PMID: 28705002. DOI: $10.21037 /$ cco.2017.06.15

11 Begg SKS, Birnbaum DJ, Clark JW, Mino-Kenudson M, Wellner UF, Schilling O, Lillemoe KD, Warshaw AL, Castillo CF and Liss AS: FOLFIRINOX versus gemcitabine-based therapy for pancreatic ductal adenocarcinoma: Lessons from patient-derived cell lines. Anticancer Res 40(7): 3659-3667, 2020. PMID: 32620605. DOI: 10.21873 /anticanres. 14355

12 Foucher ED, Ghigo C, Chouaib S, Galon J, Iovanna J and Olive D: Pancreatic ductal adenocarcinoma: A strong imbalance of good and bad immunological cops in the tumor microenvironment. Front Immunol 9: 1044, 2018. PMID: 29868007. DOI: 10.3389/fimmu.2018.01044

13 Martinez-Bosch N, Vinaixa J and Navarro P: Immune evasion in pancreatic cancer: From mechanisms to therapy. Cancers (Basel) 10(1): 6, 2018. PMID: 29301364. DOI: 10.3390/cancers 10010006

14 Tang D, Wang D, Yuan Z, Xue X, Zhang Y, An Y, Chen J, Tu M, Lu Z, Wei J, Jiang K and Miao Y: Persistent activation of pancreatic stellate cells creates a microenvironment favorable for the malignant behavior of pancreatic ductal adenocarcinoma. Int J Cancer 132(5): 993-1003, 2013. PMID: 22777597. DOI: $10.1002 / \mathrm{ijc} .27715$

15 Neutzner M, Lopez T, Feng X, Bergmann-Leitner ES, Leitner WW and Udey MC: MFG-E8/lactadherin promotes tumor growth in an angiogenesis-dependent transgenic mouse model of multistage carcinogenesis. Cancer Res 67(14): 6777-6785, 2007. PMID: 17638889. DOI: 10.1158/0008-5472.CAN-07-0165

16 Hussain F, Wang J, Ahmed R, Guest SK, Lam EW, Stamp G and El-Bahrawy M: The expression of IL-8 and IL-8 receptors in pancreatic adenocarcinomas and pancreatic neuroendocrine tumours. Cytokine 49(2): 134-140, 2010. PMID: 20005738. DOI: $10.1016 /$ j.cyto.2009.11.010

17 Zhao X, Liu Y, Li Z, Zheng S, Wang Z, Li W, Bi Z, Li L, Jiang Y, Luo Y, Lin Q, Fu Z and Rufu C: Linc00511 acts as a competing endogenous RNA to regulate VEGFA expression through sponging hsa-miR-29b-3p in pancreatic ductal adenocarcinoma. J Cell Mol Med 22(1): 655-667, 2018. PMID: 28984028. DOI: $10.1111 /$ jcmm.13351

18 Lacina L, Brábek J, Král V, Kodet $\mathrm{O}$ and Smetana $\mathrm{K} \mathrm{Jr}$ : Interleukin-6: a molecule with complex biological impact in cancer. Histol Histopathol 34(2): 125-136, 2019. PMID: 30178819. DOI: $10.14670 / \mathrm{HH}-18-033$

19 Provenzano PP, Cuevas C, Chang AE, Goel VK, Von Hoff DD and Hingorani SR: Enzymatic targeting of the stroma ablates physical barriers to treatment of pancreatic ductal adenocarcinoma. Cancer Cell 21(3): 418-429, 2012. PMID: 22439937. DOI: $10.1016 /$ j.ccr.2012.01.007

20 Hiraoka N, Onozato K, Kosuge T and Hirohashi S: Prevalence of FOXP3+ regulatory $\mathrm{T}$ cells increases during the progression of pancreatic ductal adenocarcinoma and its premalignant lesions. Clin Cancer Res 12(18): 5423-5434, 2006. PMID: 17000676. DOI: 10.1158/1078-0432.CCR-06-0369

21 von Bernstorff W, Voss M, Freichel S, Schmid A, Vogel I, Jöhnk C, Henne-Bruns D, Kremer B and Kalthoff H: Systemic and local immunosuppression in pancreatic cancer patients. Clin Cancer Res 7(3 Suppl): 925s-932s, 2001. PMID: 11300493

22 Martinez-Bosch N, Vinaixa $\mathbf{J}$ and Navarro P: Immune evasion in pancreatic cancer: From mechanisms to therapy. Cancers (Basel) 10(1): 6, 2018. PMID: 29301364. DOI: 10.3390/cancers 10010006

23 Orozco CA, Martinez-Bosch N, Guerrero PE, Vinaixa J, DalottoMoreno T, Iglesias M, Moreno M, Djurec M, Poirier F, Gabius HJ, Fernandez-Zapico ME, Hwang RF, Guerra C, Rabinovich GA and Navarro P: Targeting galectin-1 inhibits pancreatic cancer progression by modulating tumor-stroma crosstalk. Proc Natl Acad Sci USA 115(16): E3769-E3778, 2018. PMID: 29615514. DOI: 10.1073/pnas.1722434115

24 Olive KP, Jacobetz MA, Davidson CJ, Gopinathan A, McIntyre D, Honess D, Madhu B, Goldgraben MA, Caldwell ME, Allard D, Frese KK, Denicola G, Feig C, Combs C, Winter SP, IrelandZecchini H, Reichelt S, Howat WJ, Chang A, Dhara M, Wang L, Rückert F, Grützmann R, Pilarsky C, Izeradjene K, Hingorani SR, Huang P, Davies SE, Plunkett W, Egorin M, Hruban RH, Whitebread N, McGovern K, Adams J, Iacobuzio-Donahue C, Griffiths J and Tuveson DA: Inhibition of Hedgehog signaling enhances delivery of chemotherapy in a mouse model of pancreatic cancer. Science 324(5933): 1457-1461, 2009. PMID: 19460966. DOI: $10.1126 /$ science. 1171362

25 Rhim AD, Oberstein PE, Thomas DH, Mirek ET, Palermo CF, Sastra SA, Dekleva EN, Saunders T, Becerra CP, Tattersall IW, Westphalen CB, Kitajewski J, Fernandez-Barrena MG, Fernandez-Zapico ME, Iacobuzio-Donahue C, Olive KP and Stanger BZ: Stromal elements act to restrain, rather than support, pancreatic ductal adenocarcinoma. Cancer Cell 25(6): 735-747, 2014. PMID: 24856585. DOI: 10.1016/j.ccr.2014.04.021

26 Lee J, Perera R, Wang H, Wu D, Liu X, Han S, Fitamant J, Jones P, Ghanta K, Kawano S, Nagle J, Deshpande V, Boucher Y, Kato T, Chen J, Willmann J, Bardeesy N and Beachy P: Stromal response to Hedgehog signaling restrains pancreatic cancer progression. Proceedings of the National Academy of Sciences 111(30): E3091-E3100, 2017. DOI: 10.1073/pnas.1411679111 
27 Bijlsma MF and van Laarhoven HW: The conflicting roles of tumor stroma in pancreatic cancer and their contribution to the failure of clinical trials: A systematic review and critical appraisal. Cancer Metastasis Rev 34(1): 97-114, 2015. PMID: 25566685. DOI: 10.1007/s10555-014-9541-1

28 Boukamp P, Petrussevska RT, Breitkreutz D, Hornung J, Markham A and Fusenig NE: Normal keratinization in a spontaneously immortalized aneuploid human keratinocyte cell line. J Cell Biol 106(3): 761-771, 1988. PMID: 2450098. DOI: $10.1083 /$ jcb.106.3.761

29 Shrestha B and Dunn L: The Declaration of Helsinki on medical research involving human subjects: A review of seventh revision. J Nepal Health Res Counc 17(4): 548-552, 2020. PMID: 32001865. DOI: $10.33314 /$ jnhrc.v17i4.1042

30 Dvořánková $\mathrm{B}$, Lacina L and Smetana K Jr: Isolation of normal fibroblasts and their Cancer-Associated Counterparts (CAFs) for biomedical research. Methods Mol Biol 1879: 393-406, 2019. PMID: 29675784. DOI: 10.1007/7651_2018_137

31 Szabó P, Koláŕ M, Dvořánková B, Lacina L, Štork J, Vlček Č, Strnad H, Tvrdek M and Smetana K Jr: Mouse 3 T3 fibroblasts under the influence of fibroblasts isolated from stroma of human basal cell carcinoma acquire properties of multipotent stem cells. Biol Cell 103(5): 233-248, 2011. PMID: 21355851. DOI: 10.1042/BC20100113

32 Franken NA, Rodermond HM, Stap J, Haveman J and van Bree C: Clonogenic assay of cells in vitro. Nat Protoc 1(5): 23152319, 2006. PMID: 17406473. DOI: 10.1038/nprot.2006.339

33 Carvalho BS and Irizarry RA: A framework for oligonucleotide microarray preprocessing. Bioinformatics 26(19): 2363-2367, 2010. PMID: 20688976. DOI: 10.1093/bioinformatics/btq431

34 Ritchie ME, Phipson B, Wu D, Hu Y, Law CW, Shi W and Smyth GK: Limma powers differential expression analyses for RNA-sequencing and microarray studies. Nucleic Acids Res 43(7): e47, 2015. PMID: 25605792. DOI: 10.1093/nar/gkv007

35 Huber W, Carey VJ, Gentleman R, Anders S, Carlson M, Carvalho BS, Bravo HC, Davis S, Gatto L, Girke T, Gottardo R, Hahne F, Hansen KD, Irizarry RA, Lawrence M, Love MI, MacDonald J, Obenchain V, Oleś AK, Pagès H, Reyes A, Shannon P, Smyth GK, Tenenbaum D, Waldron L and Morgan M: Orchestrating high-throughput genomic analysis with Bioconductor. Nat Methods 12(2): 115-121, 2015. PMID: 25633503. DOI: $10.1038 /$ nmeth. 3252

36 Storey JD and Tibshirani R: Statistical significance for genomewide studies. Proc Natl Acad Sci USA 100(16): 94409445, 2003. PMID: 12883005. DOI: 10.1073/pnas.1530509100

37 Kanehisa M, Furumichi M, Tanabe M, Sato Y and Morishima K: KEGG: New perspectives on genomes, pathways, diseases and drugs. Nucleic Acids Res 45(D1): D353-D361, 2017. PMID: 27899662. DOI: $10.1093 / \mathrm{nar} / \mathrm{gkw} 1092$

38 Hammer O, Harper DAT and Ryan PD: Past: Paleontological statistics software package for education and data analysis. Palaeontologia Electronica 4(1): 9, 2001.

39 Monkman JH, Thompson EW and Nagaraj SH: Targeting epithelial mesenchymal plasticity in pancreatic cancer: A compendium of preclinical discovery in a heterogeneous disease. Cancers (Basel) 11(11): 1745, 2019. PMID: 31703358. DOI: 10.3390/cancers 11111745

40 Principe DR, Diaz AM, Torres C, Mangan RJ, DeCant B, McKinney R, Tsao MS, Lowy A, Munshi HG, Jung B and Grippo PJ: TGF $\beta$ engages MEK/ERK to differentially regulate benign and malignant pancreas cell function. Oncogene 36(30): 4336-4348, 2017. PMID: 28368414. DOI: 10.1038/onc.2016.500

41 Neuzillet C, de Gramont A, Tijeras-Raballand A, de Mestier L, Cros J, Faivre S and Raymond E: Perspectives of TGF- $\beta$ inhibition in pancreatic and hepatocellular carcinomas. Oncotarget 5(1): 7894, 2014. PMID: 24393789. DOI: 10.18632/oncotarget.1569

42 Ligorio M, Sil S, Malagon-Lopez J, Nieman LT, Misale S, Di Pilato M, Ebright RY, Karabacak MN, Kulkarni AS, Liu A, Vincent Jordan N, Franses JW, Philipp J, Kreuzer J, Desai N, Arora KS, Rajurkar M, Horwitz E, Neyaz A, Tai E, Magnus NKC, Vo KD, Yashaswini CN, Marangoni F, Boukhali M, Fatherree JP, Damon LJ, Xega K, Desai R, Choz M, Bersani F, Langenbucher A, Thapar V, Morris R, Wellner UF, Schilling O, Lawrence MS, Liss AS, Rivera MN, Deshpande V, Benes CH, Maheswaran S, Haber DA, Fernandez-Del-Castillo C, Ferrone CR, Haas W, Aryee MJ and Ting DT: Stromal microenvironment shapes the intratumoral architecture of pancreatic cancer. Cell 178(1): 160-175.e27, 2019. PMID: 31155233. DOI: 10.1016/j.cell.2019.05.012

43 Wang Y, Jin G, Li Q, Wang Z, Hu W, Li P, Li S, Wu H, Kong $\mathrm{X}$, Gao J and Li Z: Hedgehog signaling non-canonical activated by pro-inflammatory cytokines in pancreatic ductal adenocarcinoma. J Cancer 7(14): 2067-2076, 2016. PMID: 27877222. DOI: $10.7150 /$ jca. 15786

44 Bever KM, Sugar EA, Bigelow E, Sharma R, Laheru D, Wolfgang CL, Jaffee EM, Anders RA, De Jesus-Acosta A and Zheng L: The prognostic value of stroma in pancreatic cancer in patients receiving adjuvant therapy. HPB (Oxford) 17(4): 292298, 2015. PMID: 25250696. DOI: 10.1111/hpb.12334

45 Mathew E, Brannon AL, Del Vecchio A, Garcia PE, Penny MK, Kane KT, Vinta A, Buckanovich RJ and di Magliano MP: mesenchymal stem cells promote pancreatic tumor growth by inducing alternative polarization of macrophages. Neoplasia 18(3): 142-151, 2016. PMID: 26992915. DOI: 10.1016/j.neo.2016.01.005

46 Erdogan B, Ao M, White LM, Means AL, Brewer BM, Yang L, Washington MK, Shi C, Franco OE, Weaver AM, Hayward SW, Li D and Webb DJ: Cancer-associated fibroblasts promote directional cancer cell migration by aligning fibronectin. J Cell Biol 216(11): 3799-3816, 2017. PMID: 29021221. DOI: 10.1083/jcb.201704053

47 Ding SM, Lu AL, Zhang W, Zhou L, Xie HY, Zheng SS and Li QY: The role of cancer-associated fibroblast MRC-5 in pancreatic cancer. J Cancer 9(3): 614-628, 2018. PMID: 29483967. DOI: $10.7150 /$ jca. 19614

48 Özdemir BC, Pentcheva-Hoang T, Carstens JL, Zheng X, Wu CC, Simpson TR, Laklai H, Sugimoto H, Kahlert C, Novitskiy SV, De Jesus-Acosta A, Sharma P, Heidari P, Mahmood U, Chin L, Moses HL, Weaver VM, Maitra A, Allison JP, LeBleu VS and Kalluri R: Depletion of carcinoma-associated fibroblasts and fibrosis induces immunosuppression and accelerates pancreas cancer with reduced survival. Cancer Cell 25(6): 719-734, 2014. PMID: 24856586. DOI: 10.1016/j.ccr.2014.04.005

49 Omary MB, Lugea A, Lowe AW and Pandol SJ: The pancreatic stellate cell: A star on the rise in pancreatic diseases. J Clin Invest 117(1): 50-59, 2007. PMID: 17200706. DOI: 10.1172/JCI30082

50 Holmer R, Goumas FA, Waetzig GH, Rose-John S and Kalthoff H: Interleukin-6: a villain in the drama of pancreatic cancer development and progression. Hepatobiliary Pancreat Dis Int 13(4): 371-380, 2014. PMID: 25100121. DOI: 10.1016/s14993872(14)60259-9 
51 Kim HW, Lee JC, Paik KH, Kang J, Kim J and Hwang JH: Serum interleukin-6 is associated with pancreatic ductal adenocarcinoma progression pattern. Medicine (Baltimore) 96(5): e5926, 2017. PMID: 28151872. DOI: 10.1097/MD.0000000000005926

52 Long KB, Tooker G, Tooker E, Luque SL, Lee JW, Pan X and Beatty GL: IL6 receptor blockade enhances chemotherapy efficacy in pancreatic ductal adenocarcinoma. Mol Cancer Ther 16(9): 1898-1908, 2017. PMID: 28611107. DOI: 10.1158/15357163.MCT-16-0899

53 Xing HB, Tong MT, Wang J, Hu H, Zhai CY, Huang CX and Li D: Suppression of $I L-6$ Gene by shRNA augments gemcitabine chemosensitization in pancreatic adenocarcinoma cells. Biomed Res Int 2018: 3195025, 2018. PMID: 29693005. DOI: $10.1155 / 2018 / 3195025$

54 Guan J, Zhang H, Wen Z, Gu Y, Cheng Y, Sun Y, Zhang T, Jia $\mathrm{C}, \mathrm{Lu} \mathrm{Z}$ and Chen J: Retinoic acid inhibits pancreatic cancer cell migration and EMT through the downregulation of IL-6 in cancer associated fibroblast cells. Cancer Lett 345(1): 132-139, 2014. PMID: 24334138. DOI: 10.1016/j.canlet.2013.12.006

55 Jobe NP, Rösel D, Dvořánková B, Kodet O, Lacina L, Mateu $\mathrm{R}$, Smetana K and Brábek J: Simultaneous blocking of IL-6 and IL- 8 is sufficient to fully inhibit CAF-induced human melanoma cell invasiveness. Histochem Cell Biol 146(2): 205-217, 2016. PMID: 27102177. DOI: 10.1007/s00418-0161433-8

56 Jayatilaka H, Tyle P, Chen JJ, Kwak M, Ju J, Kim HJ, Lee JSH, Wu PH, Gilkes DM, Fan R and Wirtz D: Synergistic IL-6 and IL-8 paracrine signalling pathway infers a strategy to inhibit tumour cell migration. Nat Commun 8: 15584, 2017. PMID: 28548090. DOI: $10.1038 /$ ncomms 15584

57 Matsuo Y, Ochi N, Sawai H, Yasuda A, Takahashi H, Funahashi $\mathrm{H}$, Takeyama H, Tong $\mathrm{Z}$ and Guha S: CXCL8/IL-8 and CXCL12/SDF-1alpha co-operatively promote invasiveness and angiogenesis in pancreatic cancer. Int J Cancer 124(4): 853-861, 2009. PMID: 19035451 . DOI: $10.1002 / \mathrm{ijc} .24040$

58 Wang T, Notta F, Navab R, Joseph J, Ibrahimov E, Xu J, Zhu CQ, Borgida A, Gallinger S and Tsao MS: Senescent carcinomaassociated fibroblasts upregulate IL8 to enhance prometastatic phenotypes. Mol Cancer Res 15(1): 3-14, 2017. PMID: 27678171. DOI: 10.1158/1541-7786.MCR-16-0192

59 Chen Y, Shi M, Yu GZ, Qin XR, Jin G, Chen P and Zhu MH: Interleukin-8, a promising predictor for prognosis of pancreatic cancer. World J Gastroenterol 18(10): 1123-1129, 2012. PMID: 22416189. DOI: 10.3748/wjg.v18.i10.1123

60 Tibaldi L, Leyman S, Nicolas A, Notebaert S, Dewulf M, Ngo TH, Zuany-Amorim C, Amzallag N, Bernard-Pierrot I, SastreGarau $\mathrm{X}$ and Théry C: New blocking antibodies impede adhesion, migration and survival of ovarian cancer cells, highlighting MFGE8 as a potential therapeutic target of human ovarian carcinoma. PLoS One 8(8): e72708, 2013. PMID: 23977342. DOI: 10.1371/journal.pone.0072708

61 Plzák J, Bouček J, Bandúrová V, Koláŕ M, Hradilová M, Szabo P, Lacina L, Chovanec M and Smetana K Jr: The head and neck squamous cell carcinoma microenvironment as a potential target for cancer therapy. Cancers (Basel) 11(4): 440, 2019. PMID: 30925774. DOI: $10.3390 /$ cancers 11040440

62 Newburg DS, Peterson JA, Ruiz-Palacios GM, Matson DO, Morrow AL, Shults J, Guerrero ML, Chaturvedi P, Newburg SO, Scallan CD, Taylor MR, Ceriani RL and Pickering LK: Role of human-milk lactadherin in protection against symptomatic rotavirus infection. Lancet 351(9110): 1160-1164, 1998. PMID: 9643686. DOI: 10.1016/s0140-6736(97)10322-1

63 D'Haese JG, Demir IE, Kehl T, Winckler J, Giese NA, Bergmann F, Giese T, Büchler MW, Friess H, Hartel M and Ceyhan GO: The impact of MFG-E8 in chronic pancreatitis: Potential for future immunotherapy? BMC Gastroenterol 13: 14, 2013. PMID: 23324439. DOI: $10.1186 / 1471-230 X-13-14$

64 Liu Y, Li F, Gao F, Xing L, Qin P, Liang X, Zhang J, Qiao X, Lin $\mathrm{L}$, Zhao $\mathrm{Q}$ and $\mathrm{Du} \mathrm{L}$ : Periostin promotes tumor angiogenesis in pancreatic cancer via Erk/VEGF signaling. Oncotarget 7(26): 4014840159, 2016. PMID: 27223086. DOI: 10.18632/oncotarget.9512

65 Kanno A, Satoh K, Masamune A, Hirota M, Kimura K, Umino J, Hamada S, Satoh A, Egawa S, Motoi F, Unno M and Shimosegawa T: Periostin, secreted from stromal cells, has biphasic effect on cell migration and correlates with the epithelial to mesenchymal transition of human pancreatic cancer cells. Int J Cancer 122(12): 2707-2718, 2008. PMID: 18381746. DOI: 10.1002/ijc.23332

66 Fukushima N, Kikuchi Y, Nishiyama T, Kudo A and Fukayama M: Periostin deposition in the stroma of invasive and intraductal neoplasms of the pancreas. Mod Pathol 21(8): 1044-1053, 2008. PMID: 18487994. DOI: $10.1038 /$ modpathol.2008.77

67 Goel HL and Mercurio AM: VEGF targets the tumour cell. Nat Rev Cancer 13(12): 871-882, 2013. PMID: 24263190. DOI: $10.1038 / \mathrm{nrc} 3627$

68 Dvořánková B, Smetana K Jr, Říhová B, Kučera J, Mateu R and Szabo P: Cancer-associated fibroblasts are not formed from cancer cells by epithelial-to-mesenchymal transition in $\mathrm{nu} / \mathrm{nu}$ mice. Histochem Cell Biol 143(5): 463-469, 2015. PMID: 25387587. DOI: $10.1007 / \mathrm{s} 00418-014-1293-\mathrm{z}$

69 Pampinella F, Roelofs M, Castellucci E, Chiavegato A, Guidolin D, Passerini-Glazel G, Pagano F and Sartore S: Proliferation of submesothelial mesenchymal cells during early phase of serosal thickening in the rabbit bladder is accompanied by transient keratin 18 expression. Exp Cell Res 223(2): 327-339, 1996. PMID: 8601410. DOI: 10.1006/excr.1996.0088

70 Chang TH, Huang HD, Ong WK, Fu YJ, Lee OK, Chien S and Ho JH: The effects of actin cytoskeleton perturbation on keratin intermediate filament formation in mesenchymal stem/stromal cells. Biomaterials 35(13): 3934-3944, 2014. PMID: 24513317. DOI: $10.1016 /$ j.biomaterials.2014.01.028

71 Yang J, Xiong L, Wang R, Yuan Q, Xia Y, Sun J and Horch RE: In vitro expression of cytokeratin 18,19 and tube formation of adipose-derived stem cells induced by the breast epithelial cell line HBL-100. J Cell Mol Med 19(12): 2827-2831, 2015. PMID: 26416346. DOI: $10.1111 / \mathrm{jcmm} .12673$

72 Chen S, Wang M, Chen X, Chen S, Liu L, Zhu J, Wang J, Yang $\mathrm{X}$ and Cai $\mathrm{X}$ : In vitro expression of cytokeratin 19 in adiposederived stem cells is induced by epidermal growth factor. Med Sci Monit 24: 4254-4261, 2018. PMID: 29925829. DOI: 10.12659/MSM.908647

73 Tong J, Mou S, Xiong L, Wang Z, Wang R, Weigand A, Yuan Q, Horch RE, Sun J and Yang J: Adipose-derived mesenchymal stem cells formed acinar-like structure when stimulated with breast epithelial cells in three-dimensional culture. PLoS One 13(10): e0204077, 2018. PMID: 30335754. DOI: 10.1371/ journal.pone.0204077

Received January 26, 2021

Revised February 25, 2021

Accepted March 4, 2021 